Florida International University FIU Digital Commons

\title{
Impact of Anonymity and Social Modeling: Online Aggression in Emerging Adults and Their Religious and Political Ideologies
}

\author{
Adam Zimmerman \\ Florida International University, adzimmer@fiu.edu
}

DOI: 10.25148 /etd.FIDC004002

Follow this and additional works at: https://digitalcommons.fiu.edu/etd

Part of the Developmental Psychology Commons, and the Social Psychology Commons

\section{Recommended Citation}

Zimmerman, Adam, "Impact of Anonymity and Social Modeling: Online Aggression in Emerging Adults and Their Religious and Political Ideologies" (2017). FIU Electronic Theses and Dissertations. 3564.

https://digitalcommons.fiu.edu/etd/3564 


\title{
FLORIDA INTERNATIONAL UNIVERSITY
}

Miami, Florida

IMPACT OF ANONYMITY AND SOCIAL MODELING: ONLINE AGGRESSION IN EMERGING ADULTS AND THEIR RELIGIOUS AND POLITICAL IDEOLOGIES

A dissertation proposal submitted in partial fulfillment of the

\author{
requirements for the degree of \\ DOCTOR OF PHILOSOPHY \\ in \\ PSYCHOLOGY \\ by \\ Adam Zimmerman
}


To: Dean Michael R. Heithaus

College of Arts, Sciences, and Education

This dissertation, written by Adam Zimmerman, and entitled Impact of Anonymity and Social Modeling: Online Aggression in Emerging Adults and their Religious and Political Ideologies, having been approved in respect to style and intellectual content, is referred to you for judgment.

We have read this dissertation and recommend that it be approved.

$\begin{array}{r}\hline \text { Asia Eaton } \\ \hline \text { Bethany Reeb-Sutherland } \\ \hline \text { Yu Liu } \\ \hline \text { Dionne Stephens, Major Professor }\end{array}$

Date of Defense: August 28, 2017

The dissertation of Adam Zimmerman is approved.

Dean Michael R. Heithaus College of Arts and Sciences

Andrés G. Gil Vice President for Research and Economic Development and Dean of University Graduate School

Florida International University, 2017 


\section{DEDICATION}

This dissertation is dedicated to my nephews, Sammy and Jackson, who are currently young padawans soaking in everything they can about the complex world around them! May they one day read this and think their uncle is a cool dude. 


\section{ACKNOWLEDGMENTS}

I would like extend my deepest appreciation to my committee members, family, and co-workers who have supported me greatly along this journey.

First, I would like to thank my mentor, Dr. Dionne Stephens, for her tremendous support, encouragement, and guidance throughout my entire experience at FIU. She instilled confidence in me at every step of the dissertation process and was not only a vital mentor along my path to completion of this program but also became a great friend. I would also like to thank my committee members, Drs. Asia Eaton, Bethany ReebSutherland, and Yu Liu for believing in my research and for their significant contributions to developing the final product.

I would like to thank my parents, Jill and Ross Zimmerman, My stepmom Karin Bayne, and my siblings Stephanie, Jessica, and Josh for always being there for me with the love, support, and more than occasional pep talks that kept me motivated and passionate about my research and entire academic experience.

Also, I would like to thank all of the research assistants that assisted in collection and coding of data used in this dissertation: Gaby Gonzalez, Soany Collazo, Nathalie Perez, Brenda Melendrez, Yanet Ruvalcaba, Tesha Davilmar, Ivette Troitino, Jessica Machado, Ryan Baker, Michelle Caldera, Melissa Montero, Nilda Chery, Melissa Lowenhaupt, Alexa Collazo, Nicolas Reyes, Ajai Johnson, and Cristina Munoz.

Finally, a special thanks to Ross Berger for convincing me to pursue this line of research. Without everyone involved, this dissertation would not have been possible. 


\begin{abstract}
OF THE DISSERTATION
IMPACT OF ANONYMITY AND SOCIAL MODELING: ONLINE AGGRESSION IN EMERGING ADULTS AND THEIR RELIGIOUS AND POLITICAL IDEOLOGIES
\end{abstract}

Adam Zimmerman

Florida International University, 2017

Miami, Florida

Professor Dionne Stephens, Major Professor

This dissertation investigated online aggression in emerging adults to understand the contextual power of anonymity and social modeling. Emerging adults are characterized as undergoing a period of identity exploration, instability, self-focus, transition, and possibility (Arnett, 2004). Given the importance of identity development at this stage of the lifespan, this research explored religiosity/spirituality and political ideology; two pivotal belief systems that are introspectively evaluated and molded in emerging adults as they separate their identities from their world views (Barry \& Nelson, 2004). Furthermore, this dissertation sought to apply religiosity/spirituality and political ideology to the previously established link of anonymity and social modeling and their joined impact on online aggression (Zimmerman \& Ybarra, 2016). Behavioral temptation to aggress and participant responses following interaction on a mock blog was recorded and analyzed in situations of anonymity and positive or neutral social models. Aggressive social modeling influenced blog posts and behavioral temptation to aggress. Religiosity/spirituality and political attitudes moderated aggression in blog posts. 


\section{TABLE OF CONTENTS}

CHAPTER

PAGE

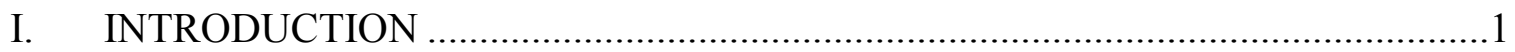

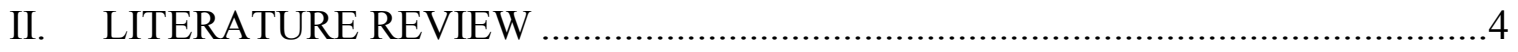

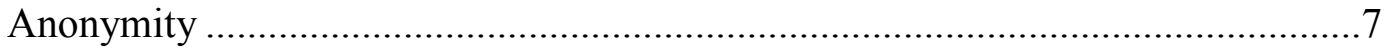

Social Modeling ..................................................................................... 9

Emerging Adulthood \& Identity Development.................................................. 12

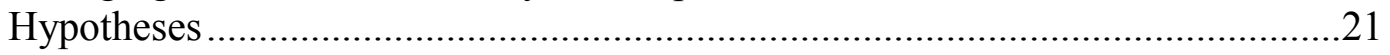

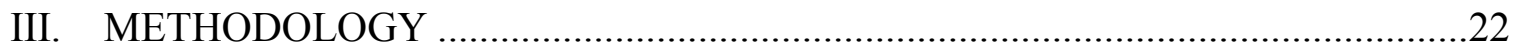

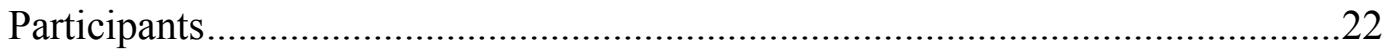

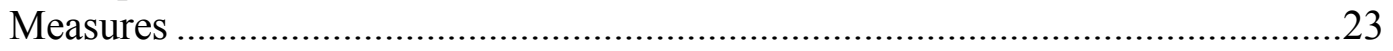

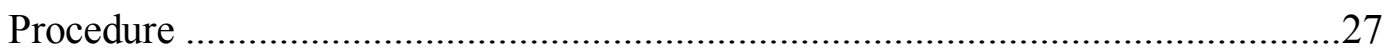

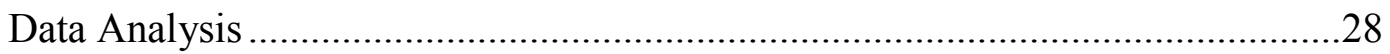

IV. STUDY 1 - Influence of Anonymity and Social Modeling on Aggression .............30

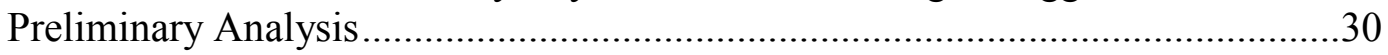

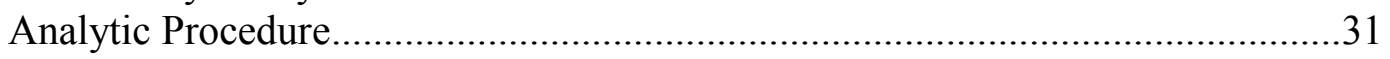

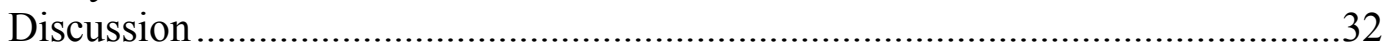

V. STUDY 2 - Political Attitudes and Religiosity/Spirituality ..................................37

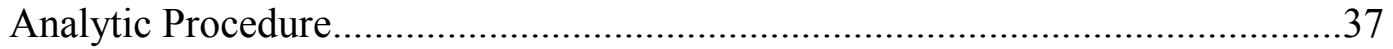

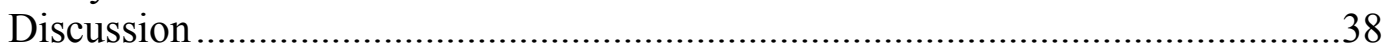

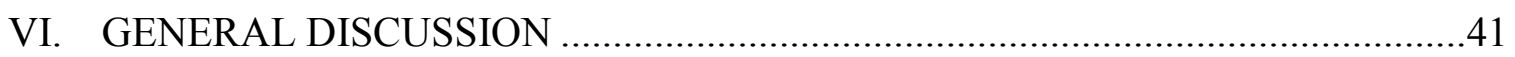

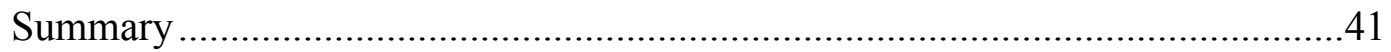

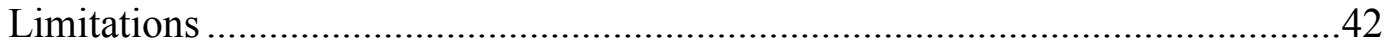

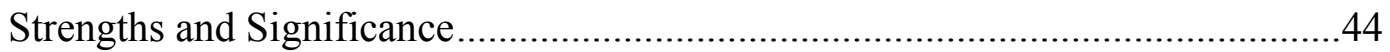

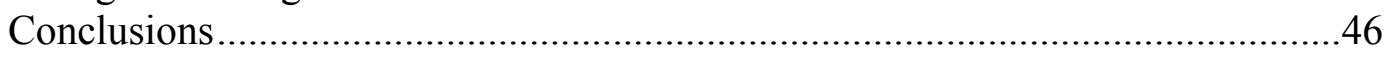

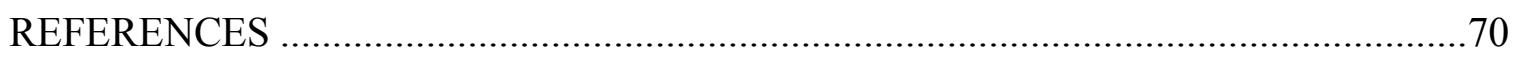

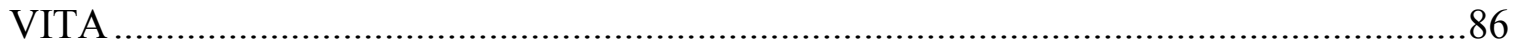




\section{LIST OF TABLES}

TABLE

PAGE

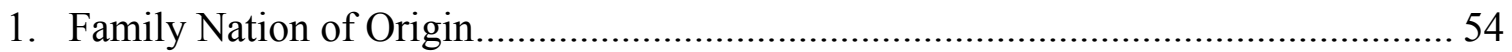

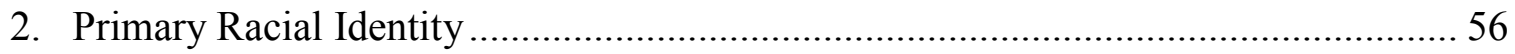

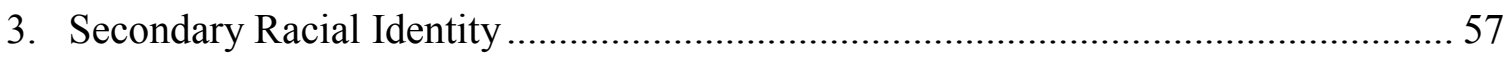

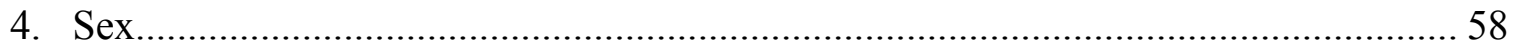

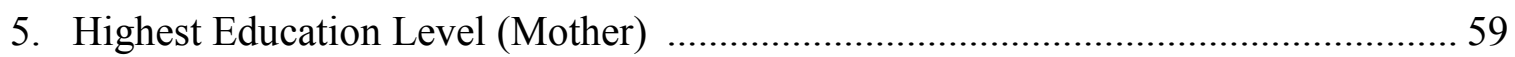

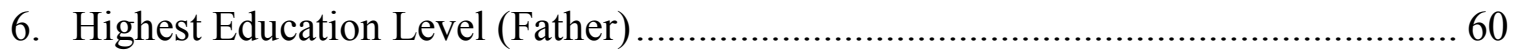

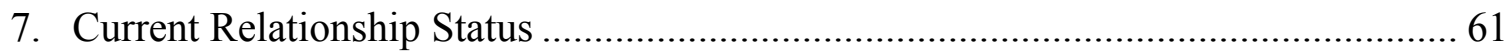

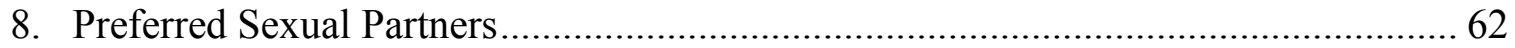

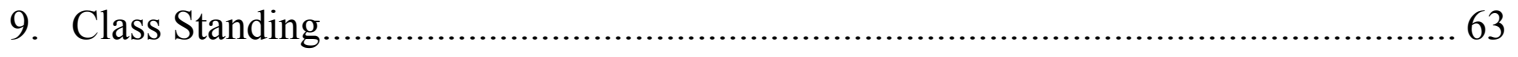

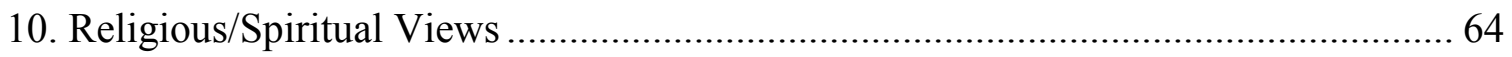

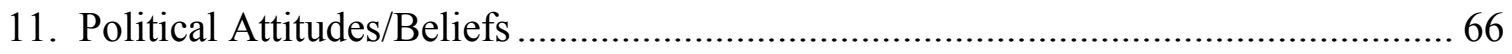

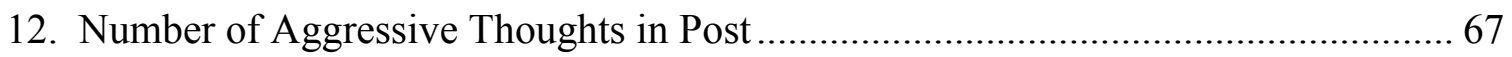

13. It is important to me that people do not think I am prejudiced ............................... 68

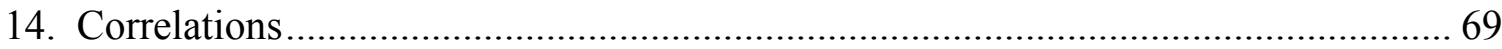

15. Appendix A - Getting to know you task (Not Anonymous) ................................... 79

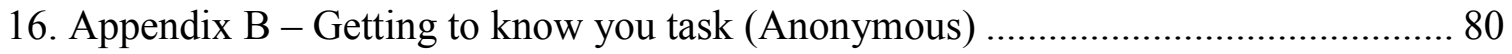

17. Appendix C - Religiosity/Spirituality Scale ................................................. 81

18. Appendix D - Political Ideologies/Values Scale .................................................. 82

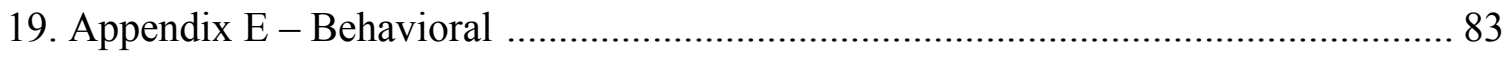

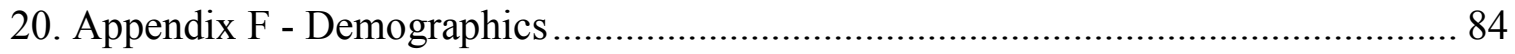




\section{INTRODUCTION}

Over the last few decades, the internet has developed into the dominant venue for communication, entertainment, and information. Users frequent news blogs and other online forums as a method for viewing and exchanging ideas on current events, politics, religion, science, and countless other topics. According to the U.S. Census Bureau (2013), 92.1\% of people between the ages of 15 and 34 years have a household with a computer. Furthermore, $74.4 \%$ of people between the ages of 15 and 34 years have some type of internet subscription. In 2015, the Pew Research Center reports $90 \%$ of young adults between the ages of 18 and 29 use some form of social media [not necessarily limited to the computer] (Pew Research Center, 2015).

While the use of Computer-mediated Communication (CMC) is beneficial for the dissemination of information and open dialogue with people across great distances, there are observable negative consequences that follow. Existing research on internet aggression, such as, the CDC's Youth Risk Behavior Surveillance in 2013, found that $15 \%$ of high school students nationwide have experienced some form of cyberbullying online, with an even higher percentage for students between $10^{\text {th }}$ and $12^{\text {th }}$ grade (Kann et al., 2013). The Youth Risk Behavior Surveillance samples high school students who attend public or private schools in 50 participating states and started addressing the topic of electronic bullying in the 2011 edition. In a breakdown of 40 states from this sample, the rate of students who reported being bullied ranged from $11.9 \%$ to $20.6 \%$ (Kann et al., 2013). Finkelhor et al.’s, (2000) study on the effects of cyber aggression noted that one-third of young adults harassed online reported feeling very or extremely 
upset, and one-third reported feeling at least one symptom of stress following the occurrence (Finkelhor et al., 2000).

What might be even more important to consider is the factors that influence the perpetration of online aggression. Studies report that approximately 15\% people admit to having been an online aggressor at least once in the previous year (Ybarra \& Mitchell, 2004). It is suggested that appeal of being aggressive in virtual worlds stems from the sense of escapism users can experience, and their ability to disconnect from the hackneyed "real world" (Yee, 2006). The cyber-disinhibition phenomenon (Suler, 2004) explains the negative consequences that anonymity and sense of escapism can produce; including non-normative and inappropriate behaviors that individuals typically would not display if they were interacting face-to-face (FtF).

Despite the obvious benefits of CMC, many website comment sections reveal emotional exchanges and intense vulgarity that can occur, with larger-scale immersive virtual environments displaying even more extreme expressions. While examinations of CMC generally focus inwardly on the anonymous user (i.e., Christopherson, 2007; McKenna \& Bargh, 2000; Moral, Canto \& Gómez, 2007), the current investigation focuses on two contextual components of social interaction via CMC: Anonymity and Social Modeling and their association with online aggression.

Building upon prior anonomity and social modeling research, this dissertation examines college students' online agression beheaviors in response to a stimulus current event news story. Specifically, this dissertation first investigated behavioral temptations and aggressive thoughts on a mock forum. How these behaviors occur across anonymous (or not anonymous) groups and exposure to aggressive, neutral/positive, or no models 
was assessed. Given that identity development is tremendously crucial in the emerging adulthood stage of the lifespan, it is further particularly important to assess those identity level values that previous research has noted as influencing anonymity and opinions in this population. For this reason, exploratory questions addressing the possible influence of religiosity and conservatism were examined. 


\section{LITERATURE REVIEW}

The current cohort of emerging adults have unique tools for communication and self-expression that were not available to prior generations. Prior to 2004, cellphones, online social media sites, and general internet usages were not a normative part of adolescence through emerging adults' daily lives (Lenhart, 2009; Mitchell, Wolak, \& Finkelhor 2007). Today, online social media usages are the norm, even among children; further, usage of these tools increases steadily as children transition through developmental stages into emerging adulthood (Lenhart, 2009; Mitchell et al. 2007). Recent longitudinal data has noted that social media usage and engagement is on the rise, particularly among 18 to 29 years olds in the United States (Greenwood, Perrin, \& Duggan, 2016). In fact, $61 \%$ of students in graduate school report social media usage, this cohort's engagement in this genre is significantly higher than students in high school (40\%), college (41\%), or those who are not in college and have never attended $(41 \%$; Greenwood, Perrin, \& Duggan, 2016).

Along with increased social media usage have come technological advances that allow for even greater independent communications. In the past decade, there have been rapid technological changes that have made opportunities to communicate using online tools more accessible and easy (Brown, 2006; Lenhard, 2009). This has coincided with online communication becoming an important and integral part of communication and self-expression among emerging adults (Brown, 2006; Cicchirillo, Hmielowski, \& Hutchens, 2015; Yee, 2006). For example, Yee (2006) found that individuals have widely varying reasons for playing online games, or engaging in social interaction. In this particular study by Yee (2006), online players were asked questions about their 
motivations for online play, which revealed several components. One component is achievement, which includes the desire to advance through the game (gaining power and status), having an interest in understanding the underlying mechanics and system of gameplay, and challenging and competing with other players. The second component is for social reasons, including the desire to form meaningful relationships with other individuals, helping and chatting with other players, and gaining fulfillment from being a part of a larger group effort. Lastly is the immersion component, which consists of exploring and learning things that other players might not be privy to, role-playing different roles and interacting with other individuals to create unique and customizable stories, and the escapism that using online environments provide us with to avoid or distract from real-life problems (Yee, 2006). Any of these three components alone do not necessarily detract importance from the others.

Related to self-expression on the internet is the relevance of understanding the role of social modeling and anonymity's influence on these processes. While social modeling has been examined for a prominent portion of psychology's history (Bandura, Ross, \& Ross, 1961; Baron, 1977; Prentice-Dunn \& Rogers, 1980), human beings have undergone significant social change in the last couple of decades, for example - the development of the internet, and the increasing rate at which people are communicating anonymously online. This change has led to a growing body of research examining social modeling, anonymity, and internet communication (Christopherson, 2007; Eastwick \& Gardner, 2009; Hayne \& Rice, 1997; Reicher et al., 1995; Robertson, 2006; Spears \& Lea, 1992; Tanis \& Postmes, 2007; Yee, Bailenson, Urbanek, Chang, \& Merget, 2007). Much of this research has been spurred on by concerns that a portion of 
online communication evokes the worst of human behavior, i.e., cyberbullying and/or stalking (Apollo, 2007; Burgess-Proctor, Patchin, \& Hinduja, 2009; Li, 2007).

Oftentimes, researchers and the media classify individuals who engage in anonymous online environments into one collapsed prototype - that of aggression and addiction (Yee, 2006). However, it is important to understand that different online environments can give rise to different behavioral outcomes and specifically choosing one over the other can have strikingly dissimilar consequences. In other online environments (inclusive of gaming), individuals often use anonymity and lack of face-to-face communication to lower feelings of self-consciousness and control their social anxiety (Morahan-Martin \& Schumacher, 2003). In a particular study assessing social uses for the internet, loneliness was linked to an increase in social Internet use (Morahan-Martin \& Schumacher, 2003). Undergraduate internet users were surveyed to distinguish between lonely and non-lonely scores on the UCLA Loneliness Scale (Russell, Peplau, \& Ferguson, 1978). Undergraduates that scored higher in loneliness were more likely to self-report actively making online friends and using messaging more than non-lonely students (Morahan-Martin \& Schumacher, 2003).

Thus, it is important to note that some virtual environments where individuals place themselves in can be exceedingly violent, with some other environments being calm, social gatherings. In many virtual environments, individuals interact with anonymity, which seems to provide a variety of social benefits ranging from security and privacy to behavioral change such as an increased propensity to openly engage in social activity. This security and privacy can lead to positive interactions where individuals feel free to discuss personal health or social issues (Fox \& Duggan, 2013), 
and actively seek help and advice from others on open-access, moderated internet support forums (Griffiths, Carron-Arthur, Reynolds, Bennett, \& Bennett 2017). According to Jessup, Connolly, and Tansik (1990), anonymous groups contribute to an increased productivity in an experimental setting. Non-anonymous groups, on the other hand are seen as more personal, but seem to lack the same degree of cohesion that anonymous groups do (Tanis \& Postmes, 2007). For this reason, it is important that research examine the social forces that are impacted by the anonymous and socially modelled internet world.

\section{Anonymity}

As a construct, anonymity is commonly thought of as the state of an individual who is unknown, or lacks visible identifiable information that others can pick up on to determine an identity. Social Anonymity and Technical anonymity are two distinctions that Hayne and Rice (1997) define that separate the larger construct into sub-types. In a social setting, when there is an absence of cues that could lead to the attribution of an identity to a specific individual, it is referred to as Social Anonymity (Hayne \& Rice, 1997). Picturing the atmosphere of a dark, crowded night club, where the music is loud and visibility is poor, demonstrates the social anonymity sub-type. Voice, personality, body language, and facial features cannot be determined in such a setting. On the other hand, Technical Anonymity refers to more concrete information that allows one to pin an identity to an individual (Hayne \& Rice, 1997). Social security numbers, telephone numbers, home or IP addresses, full names, or birth dates are examples of concrete indications of identity that are nonexistent in situations of technical anonymity. These concrete forms of identity are absent in media forums, blogs, online gaming, e-mail, 
and instant messaging settings. All of these previously mentioned environments are settings in which both of these sub-types of anonymity can be present.

The privacy that anonymity affords can occur in a large crowd or even in the comfort of one's own home behind the shield of a computer screen and an internet connection. An extreme version of anonymity is outlined by Zimbardo's (1969) deindividuation study where participants shocked confederates more powerfully when their identity was concealed in comparison to when their identity was broadcasted. This uncharacteristic behavior is also exemplified in the posts made to forums and blogs on the internet under anonymous usernames and disguised avatars. Sexism, racism, and homophobia are commonplace on such anonymous forums where posters use offensive language to push the limits of decorum and gain attention (Bernstein, MonroyHernandez, Harry, Andre, Panovich, \& Vargas, 2011; Boyd, 2010). In a study by Bernstein et al. (2010), they investigated individuals who contribute posts on a large online community, 4chan.org. Of the approximately 5,147,000 posts analyzed, 90.1\% were posted under the default name "Anonymous", while 98.3\% percent of posts did not contain a corresponding e-mail address of the poster. In addition to the dominance of anonymous posters, content in this particular online community can be crude, antisocial, and invokes disinhibition (Bernstein et al., 2010). Using the guise of anonymity, users feel safer when acting in more extreme ways that they would never act offline because they can be relatively sure their actions will not come back to haunt them (Bernstein et al., 2010). It is clear that anonymity has the potential to promote deindividuation and mob behavior, especially in online environments where posts are ephemeral and can be quickly drowned by other posts in this rapid-content environment 
(Bernstein et al., 2010). When individuals are free to experiment with behaviors and even mimic other anonymous users who are expressing their own freedom to "emotionally purge" (Christopherson, 2006), they are given permission to behave defiantly without repercussion. Hiding behind the guise of unaccountability can lead to seemingly endless possibilities of aggressive internet behavior. One study even goes as far as to suggest that revealing user's names and reputations promotes pro-social behavior online (Millen \& Patterson, 2003). When participants were aware that the identities would be revealed and they would subsequently meet town residents, they engaged in more polite conversations online and less disruptive discourse such as flaming (Millen \& Patterson, 2003). Revealing the identity of participants guaranteed that participants were accountable for their words and thus led to more polite and friendly conversation (Millen \& Patterson, 2003). However, even in an online environment as crude as 4chan.org's “/b/" discussion board, the disinhibition provided by anonymity can lead individuals to start (and contribute to) advice and discussion threads (Bernstein et al., 2010). Concealment of identity here is important for preserving one's outward image. If users happen to be ignored or verbally punished for starting threads that are monotonous or embarrassing, they can be sure that anonymity will conceal their failures.

\section{Social Modeling}

The synchronous nature of anonymity and social modeling in virtual environments should urge researchers to broaden their focus and measure other factors that are acting concurrently, rather than limiting our explanation of online behavior to anonymity alone. One study (Zimmerman \& Ybarra, 2016) found evidence for the 
influence of social modeling on the link between anonymity and online aggression, such that anonymous individuals who are exposed to aggressive models were more likely to aggress themselves. Most settings on the internet contain both an anonymous component (with the exception of Facebook and other social media tools that incorporate real identities) as well as a social modeling component. In the classic Bobo doll experiment (Bandura, Ross, \& Ross, 1961) exposure to aggressive adult models led to children mimicking and eventually learning observed behavior. The similar sense of unaccountability experienced by anonymous users is experienced by those who are modeling behavior they have observed in other individuals. Other research (Baron, 1977; Prentice-Dunn \& Rogers, 1980) has established the link between exposure to aggressive models and the disinhibiting effects associated with observational learning from these models.

Arguably, if we can detect behavioral cues and eventually pick up behaviors from other individuals in FtF interactions, observational learning from anonymous individuals on the internet should occur as well. According to Smith and Berge (2009), users who engaged in the immersive virtual environment (IVE) of Second Life constantly engaged in "lurking" behavior (closely shadowing other users) when contemplating or attempting new activities with their avatars. Users would follow other anonymous users as they carried out tasks and even became students to learn how to navigate their avatars and perform similar observed tasks with others. Eventually, frequent observation resulted in behavior modeling on Second Life (Smith \& Berge, 2009). Additionally, a study by Pauwels and Schils (2016) assessed political violence and online aggression as it directly related to contact with online communication 
extremism. Participants in this study self-reported whether or not they sought out online communication extremism actively, were passively exposed to it, and the degree to which they participated in extremist moral discussions on various social media mediums. Active contact, passive exposure, and online communication extremism were all associated with higher self-reported political violence (including violence towards property, during protests, or threatening/attacking someone on the internet for their political or religious belief) even when controlling for self-control and other individual characteristics (Pauwels \& Schils, 2016).

In turn, frequent anonymous interactions in the internet world with other users can also certainly be a positive experience. Groups that are sometimes socially sanctioned like homosexuals (McKenna \& Bargh, 2000), as well as some political and religious groups, can have newsgroups that allow CMC users to freely post their ideas and feelings for others to read and reply (McKenna \& Bargh, 1998). For individuals that have stigmatized illnesses, dysfunctions, or identities (Frable, 1993), identification in FtF interaction is difficult and perhaps non-existent. Newsgroups, forums, and online support groups help these individuals (who are typically concealing their identities) find others who support and befriend them. Nevertheless, disruptive individuals posting under the guise of unaccountability and anonymity can inject hateful contributions to such online media websites and influence others to behave aggressively, engaging in flaming and "trolling" behavior to experiment with their internet autonomy. There is much left to be examined in the realm of online aggression and the simultaneous influences of social modeling and anonymity. 


\section{Emerging Adulthood \& Identity Development}

There are various factors that may play a role in anonymity and social modeling's effect on aggression in the internet world. One key factor that has been identified is stage of development in the lifespan. Individuals at different ages use the internet for different purposes, and specifically, their self-perception of online experiences and expressions should reflect their current identity development stage (Baumgartner, Valkenburg, \& Peter, 2010). Adolescents for example, take more risks in their self-presentations online when compared to adults and they have been found to be more vulnerable (Baumgartner, Valkenburg, \& Peter, 2010). Furthermore, adolescents are more likely than adults to use the internet for leisure activities (Hasebrink et al., 2008; Livingstone \& Haddon, 2008; Willoughby, 2008). Lastly, only $53 \%$ of American adults over, the age of 65 use the internet as compared to all other groups (82\%; Zickuhr \& Madden, 2012).

Although there is a clear need to consider stage of development, there is little research that specifically focuses on emerging adult populations, despite their unique position during adolescence (age 12-17) and adulthood (over age 26). The emerging adulthood phase of the lifespan (age 18-25) would be particularly important to examine as it is characterized as a period of identity exploration, instability, self-focus, transition, and possibility (Arnett, 2004). Individuals in the transition stage of emerging adulthood generally report feeling "in between" (Arnett, 2004), and feel more responsible for themselves away from their parents. Emerging adults strive for autonomy and the internet is exactly the environment that supports the free experimentation of behavior and its impact on other people from around the world. Pedersen (1997) investigated the 
importance of individuals seeking and maintaining privacy and anonymity in order to control the level of personal information that others are privy to. Of the many factors and sub-factors of privacy that were explored (see Pedersen, 1997 for a full review), two stand out as highly relevant to emerging adults undergoing a period of identity exploration and using the internet as the ideal medium for this exploration. The first factor is that of autonomy. The autonomy that privacy can offer us sparks opportunities to experiment with new behaviors without fear of social repercussions or disapproval. Using the internet as a space to explore their autonomy safely allows individuals to experiment with behaviors that differ from their usual "role," break social norms, summon creative improvisation, and lower inhibitions. The second factor of privacy and anonymity that is particularly appropriate in emerging adult's identity exploration is Catharsis. Catharsis involves the ability to confide in others, free expression of emotions, experiencing and understanding successes and failures, and planning future social interactions (Pedersen, 1997). Taken together, the free behavioral experimentation and emotional purging that anonymity provides can assist emerging adults in ultimately determining who they are and how they want to behave in the future. Clearly, the internet is wrought with social groups to sample information from and receive model behavior from, all within the protection of the freedom from accountability provided by an anonymous environment.

Undoubtedly, examining online anonymity and social modeling's effects on behavior during emerging adulthood is particularly important given their usage of this medium. The 2012 Pew Research Internet Project reports 97\% of American adults age 18-29 use the internet, $87 \%$ of which go online in a typical day. In addition to this, the 2015 edition of the Pew Research Center reports that $90 \%$ of young adults between the 
ages of 18 and 29 use some form of social media [not necessarily limited to the computer] on the internet (Pew Research Center, 2015).

The autonomy afforded by anonymity and privacy (previously mentioned) is particularly applicable to this age group as this is a time when individuals work to solidify their world views, including religious/spiritual questions, moral decisions, and political affiliations. In order to accomplish this, they must combat or accommodate to the expectations that their culture has in exploring multiple options of one's life.

Political attitudes. With the increasing number of young voters showing up on election days to cast their ballot (Snell, 2010), political attitudes are an important topic under investigation. Political decision making in emerging adults leads them to try out new behaviors like supporting or bashing a particular candidate or simply discussing political views with other individuals (Cooper, 2014). Venues of information like television viewing and (more relevantly) social media on the internet highly influence emerging adults during this political decision making process (Brown, 2006). One of the tasks for an emerging adult's development is to form an ideology and worldview that may encompass a wide range of essential beliefs and behaviors (Cooper, 2014). The development of political attitudes and behaviors lead emerging adults to move beyond a self-centered view and more toward a connectedness beyond their own needs and desires. When emerging adults are asked how they understand their involvement with politics, most describe themselves as disengaged and lacking involvement [regardless of whether or not they participate in elections] (Snell, 2010). However, emerging adults are in a stage where evaluation of governmental policies, voting behaviors, and determining a partisan preference leads to a crystallization of political identity once they reach full adulthood (Arnett, Ramos, \& 
Jensen, 2001; Bynner, 2005; Jennings, 1989; Snell, 2010). In addition to the importance of studying political attitudes in emerging adults, conservative political attitudes have been linked to aggression with individuals who score higher on conservatism versus liberalism measures displaying more aggression (for more on political preferences, see Adorno, Frenkel-Brunswik, Levinson, \& Sanford, 1950; Altemeyer, 1988; Johnson, McDermott, Cowden, \& Tingley, 2012). Discussions and debates about politics generally bring about a recipe for disagreement and potential frustration. However, in an online environment, the synchronous nature of anonymity and social modeling cues might intensify political discussion. Paying attention to other individuals who engage in aggressive discourse on political blogs, columns, or talk radio might cultivate beliefs that using aggressive language when talking about politics online is acceptable behavior (Cicchirillo et al., 2015). According to O'Sullivan and Flanagin (2003), political "flaming" involves hostile and aggressive interactions typically found in comment sections and forums transmitted through computer-mediated communication. Additionally, in an anonymous online environment where accountability is diminished or even removed completely, it seems logical that cyber-disinhibition may also be a substantial culprit in political and other forms of flaming.

Religiosity/Spiritual attitudes. According to Miller and Thoreson (2003), religiousness or religiosity is defined as an individuals' adherence to beliefs, practices and/or precepts of a particular religion. Religiosity is typically rooted in the institutional or sociological phenomenon of religion, whereas spirituality is not necessarily rooted in religion and focuses on the immaterial components of our lives that are not necessarily perceived by the physical senses (Miller \& Thoreson, 2003). For example, one might 
denounce or condemn the Bible and may avoid going to church altogether, but still feel a spiritual connection with a God or higher power and be strongly committed to living their lives with a spiritual connection in the absence of institutional religion. Religiosity is often conceptualized by the degree to which an individual follows a particular set of religious doctrines and spirituality can occur either in conjunction with religion or independently. Thus, operational definitions of religiosity and spirituality often overlap and it is advantageous to combine the two categories, not only because they have high overlap, but they include both group [religious/institutional] and individualistic nature of spirituality (Yonker et al., 2012). Yonker et al. (2012) propose a uniting conceptualization of spirituality and religiosity as "an active personal devotion and passionate quest largely within the self-acknowledged framework of a sacred theological community." For the purposes of this study, we aim to combine and investigate both constructs together.

Religious participation and spiritual faith are distinctly important concepts in emerging adults due to the fact that emerging adults are in a process of separating their identities from their world views during the transition to adulthood (Barry \& Nelson, 2004). According to Barry and Nelson (2004), college students question the beliefs in which they were raised, place greater emphasis on individual spirituality than affiliation with a religious institution, and pick apart aspects of a religion (or religions) that suit them best. This critical and investigative thinking during the transition to adulthood typically results in a decline of religious and spiritual practices such as decreased attendance of religious services and decreases in religious affiliation (Barry \& Nelson, 2010). In contrast with this waning in religious affiliation and/or attendance, research utilizing the Higher Education Research Institute (HERI) student surveys revealed that $37.9 \%$ of college 
students strengthened their religious/spiritual convictions and beliefs, $48.3 \%$ reported no change, and $13.7 \%$ weakened over the course of 4 years (Lee, 2002). In addition, $61 \%$ of students strengthened their commitment to integrating spirituality into their lives while only $20 \%$ reduced their level of commitment (Lee, 2002.). From the literature, it is clear that college students do indeed show increases in religious and spiritual beliefs, but declines in religious and spiritual practices.

In addition to the significance of studying religiosity in emerging adults, research examining religiosity and its impact on aggression is inconclusive to say the least. For example, Grasmick, Bursik, \& Kimpel (1991) found that Protestant fundamentalists with high biblical literalness are more likely to advocate corporal punishment. Furthermore, Ellison, Bartkowski, \& Anderson (1999) report that men holding more conservative theological views were more likely to perpetrate domestic violence. In contrast, they also found that regular attendance at religious services was negatively correlated with perpetration of domestic violence for both men and women. Additionally, there are also several studies that support the idea that religiosity breeds harmony and promotes nonviolent behavior (e.g., Pettersson, 1991; Powell, 1997). In support of the positive influence of religiosity and spirituality, Koenig (2008) reports that spirituality and religiosity in adults is associated with lower levels of depression and in conjunction, increases in wellbeing and self-esteem. Differences in operational definitions and the measures used in these studies may be the cause for the lack of more decisive connections between religiosity and aggression (Landau et al., 2002).

Despite evidence showing their relevance to aggression outcomes, religious and political attitudes have not been explored in research examining online aggression within 
emerging adult populations. This is concerning given this population is particularly vulnerable to online aggression because of their substantial utilization of $\mathrm{CMC}$ and the intrinsic benefits associated with free and unhindered anonymous interaction. For these reasons, it is important to study the emerging adult population in online environments. For example, Jost et al., (2003) explains that human societies strive to minimize group conflict by developing ideologies and belief systems to justify the dominance of some groups over others. Paternalistic, reciprocal, and sacred myths are the ways in which individuals can legitimize this supremacy or power over other groups (Jost et al., 2003). These legitimizing myths are particularly important in a conservative individual's arsenal (Jost \& Banaji, 1994). Intolerance, dogmatism, and close-mindedness are vastly associated with conservative, right-wing attitudes, which could provide further insight into the aggressive behaviors of anonymous individuals on the internet who share these attitudes. However, it seems that these theories of system justification and social dominance orientation might apply differently to individuals and groups interacting in virtual environments. In situations where identity is shrouded, there is more ambiguity as to which group a particular user belongs to in "real life." This study seeks to address this void in the literature by exploring the impact of different ideologies on anonymous online behavior, paying particularly attention to the role of political and religiosity attitudes among emerging adult populations.

\section{Theoretical Orientation}

As discussed in earlier sections, the theoretical orientations guiding this study include social modeling (Bandura et al., 1961) and Zimbardo's (1969) theory of deindividuation (labeled anonymity for the purposes of this study). 
The theory of deindividuation explains that individuals who have their identities concealed will be more likely to engage in counter-normative behavior and in extreme cases, aggressive or negative behaviors. This translates to modern cyber-disinhibition where individuals are more likely to display inappropriate or uncharacteristic behavior with the guise of unaccountability that most virtual environments provide. Cyberdisinhibition has been extended to the term "toxic disinhibition" by Suler (2004) to describe online-specific flaming and other damaging behaviors that involve attacks to other's self-image, values, or beliefs and opinions. Furthermore, this extends to the modern reinterpretation of classic de-individuation theory, which places more emphasis on the social variables in specific situations (Christopherson, 2007; Spears \& Lea, 1992). The Social Identity Model of Deindividuation Effects (SIDE) theory predict that situations wrought with anonymity and lack of identifiable information lead individuals to express their own personal identity and ignore the typical impact that social norms have on our behavior (Spears \& Lea, 1992). This can be particularly important and strategic for members of marginalized groups to resist a more powerful majority group (Spears, Lea, Corneliussen, Postmes, \& Haar, 2002), especially when their views may contradict the more popular majority group. Another use of anonymity as predicted by SIDE theory is exemplified in anonymous discussion boards where vengeful retaliation and hateful, unpopular opinions are expressed. SIDE theory further predicts that anonymity is used strategically to vent non-normative statements safely and without identifiable repercussion (Spears \& Lea, 1992).

Bandura's social modeling theory asserts that exposure to aggressive models can lead to mimicking and eventually learning observed behavior (Bandura, Ross, \& 
Ross, 1961). The link between exposure to aggressive models and disinhibiting effects associated with learning from these models has been exhaustively documented by other research as well (Baron, 1977; Prentice-Dunn \& Rogers, 1980). Bandura (1997) explains that there are two types of social learning processes: Observational learning and reinforcement learning. Observational learning involves the surveillance of behaviors from other individuals in order to learn how they are executed and how they might replicate such behavior. Reinforcement learning, on the other hand, highlights learning through the consequences of one's own behavior through the impact it has on other individuals who are impacted by said behavior. Individuals tend to learn new behaviors, values, and attitudes observation and modeling of peers. The similar sense of unaccountability experienced by anonymous users is also experienced by those who are modeling behavior they have observed in other individuals online. Evidence for observational learning through other anonymous models can be seen on the internet in immersive virtual environments like Second Life for instance (Smith \& Berge, 2009). Users consistently engage in shadowing behaviors when deciding whether to engage in new activities with their avatars (Smith \& Berge, 2009). Bandura's theory of social modeling thrives on the internet - where online users pick up cues from other anonymous individuals about how to behave. Together, social modeling and the theory of deindividuation are useful in the present study to explain aggressive behavior, as prior research has attempted to combine these two concepts (i.e., SIDE theory, Spears \& Lea, 1992; Spears et al., 2002). 


\section{Hypotheses}

The goal of the proposed study is to quantify the impact of anonymity and social modeling on emerging adults' aggression. There are three hypotheses of this study and one exploratory research question:

H1: Anonymity: Anonymous individuals will behave more aggressively than individuals who are not anonymous. This outlines the construct of cyberdisinhibition.

H2: Social Modeling: Individuals will display more aggression when exposed to aggressive individuals on the internet in comparison to neutral models or no models at all.

H3: Combinative effects: Replicating previous research (Zimmerman \& Ybarra, 2016), aggressive behavior should be maximized in situations that contain both components of anonymity and aggressive social models

Exploratory question: What will these combinative effects look like in individuals who fall in different spectrums of religiosity/spirituality, and the conservatism-liberalism scale? 


\section{METHODOLOGY}

\section{Participants}

Approximately seven-hundred emerging adults (ages 18-25) were recruited and sampled from a population of undergraduate students attending Florida International University. Students were required to be 18-25 years of age and were recruited using Sona System, an electronic subject pool administered by the FIU Department of Psychology. Participation incentives consist of 1 hour of extra credit for a psychology course. Informed consent was obtained prior to participating in the study.

A total of $412(57 \%)$ women and $311(43 \%)$ men participated in this study.

Familial nations of origin varied widely with 169 (23.4\%) self-identifying as Cuban, 119 (16.5\%) self-identifying from the United States, 54 (7.5\%) self-identifying as Colombian, 28 (3.9\%) self-identifying as Venezuelan, 25 (3.5\%) self-identifying as Nicaraguan, 20 (3.0\%) self-identifying as Dominican, 15 (2.1\%) self-identifying as Puerto Rican, and the other $293(40.5 \%)$ self-identifying as being from various South American and Caribbean countries (see Table 1). Racial identity self-reports indicated that the majority of participants identified their primary racial identity as Hispanic/Latin American (414; 57.3\%), followed by Black/African Descent (140; 19.4\%) followed by White nonHispanic/Caucasian (95; 13.1\%), Asian (36; 5.0\%), Other (35; 4.8\%), and Indigenous/Native (3;0.4\%) (see Tables 2 and 3). Due to rounding, these percentages may not add up to $100 \%$.

Participants most often reported their mothers' highest level of education to be a bachelor's degree (21.6\%), followed by Some College (20.1\%), High School/GED (19.4\%), Associate’s Degree (15.5\%), Master's Degree (11.5\%), Some High School 
(4.6\%), Doctoral Degree (3.6\%), Some Graduate School (1.9\%), and less than high school (6.6\%; see Table 5). When considering fathers' highest level of education, participants most often reported their fathers' highest level of education to be a High School/GED (24.9\%), followed by Bachelor's Degree (22.1\%), Some College (17.7\%), Master's Degree (11.6\%), Some High School (7.2\%), Associate's Degree (6.9\%), Doctoral Degree (5.5\%), Some Graduate School (1.9\%), and less than high school (2.0\%; see Table 6). Due to rounding, these percentages may not add up to $100 \%$.

When considering their relationship status and experience, the majority of participants reported they were Single, not dating $(279 ; 38.6 \%)$, followed by Single, dating casually $(150 ; 20.7 \%)$, In a relationship lasting longer than 2 years $(114 ; 15.8 \%)$, In a relationship less than 2 years $(85 ; 11.8 \%)$, In a relationship lasting less than 6 months (49; 6.8\%), Married (32; 4.4\%), and Engaged (14; 1.9\%) (see Table 7). Relatedly, participants preferred sexual partners were Males $(399 ; 55.2 \%)$ followed by Females (301; 41.6\%), and Both $(23 ; 3.2 \%)$ (see Table 8). Finally, the majority of participants were Juniors (29.5\%), followed by Freshman (27.9\%), Seniors (23.4\%), Sophomores (14.8\%), and "senior plus/other" (4.4\%; see Table 9). Due to rounding, these percentages may not add up to $100 \%$.

\section{Measures}

Anonymity Manipulation. Participants provided personal information if randomly assigned to the not-anonymous condition (first name, last name, living location, college major, and other personal questions [i.e., Where can you typically be found on campus? Do you find it difficult or easy to meet people?]). Participants who 
were anonymous completed a modified questionnaire that asks filler questions about participant's perception of FIU students in general, rather than themselves. To further satisfy the anonymity manipulation, users engaged in the experiment as a "GUEST" if anonymous, or told that the personal information they provided would be revealed to others in the study in following sections if they are not anonymous.

Mock News Blog. Participants were shown a link to a stimulus incident that featured recent news story. Specifically, in 2014 National Basketball Association (NBA Clippers team owner, Donald Sterling, was recorded by his mistress, V. Stiviano, detailing his obvious racist beliefs towards African-Americans. During the taped telephone conversation, Donald explicitly tells his girlfriend not to interact with Black people in public. Released by $\underline{T M Z}$ Sports, Sterling expressed annoyance that Stiviano had posted a photo of herself posed with Basketball Hall of Fame player Magic Johnson on Instagram. Key aspects of the recording heard by participants included the statements "It bothers me a lot that you want to broadcast that you're associating with black people," and, "You can sleep with [black people]. You can bring them in, you can do whatever you want...privately," but "the little I ask you is ... not to bring them to my games." This story evokes the issues of both race/discrimination and privacy. The purpose of the blog was to make the experiment appear real, including actual aggressive or neutral posts from other individuals who have viewed the same news video in the past. Further, the specific phenomenon of racial aggression is applicable, and was assessed in the study. 
Following exposure to the Donald Sterling news video and neutral or aggressive posts, all participants had an opportunity to write about their own views and reactions or respond to other's posts on a mock FIU Media News Blog.

Political Conservatism/Liberalism. The Right-Wing Authoritarianism Scale (Manganelli-Rattazzi, Bobbio, \& Canova, 2007) was used to examine participants' political views of conservatism and liberalism. This likert scale $(1=$ Strongly Disagree and $6=$ Strongly Agree) includes questions such as: "What our country really needs instead of more 'civil rights' is a good stiff dose of law and order," "We should support birth control clinics setup by the government," "Disobedience to religious authorities leads to chaos and anarchy," "We should help disadvantaged groups to secure equal rights." This scale was presented to the participant before the manipulations occur. Cronbach's $\alpha$ for all subscales of conservatism and authoritarianism $>0.7$.

Religiosity and Views of Suffering. Unterrainer, Nelson, and Fink's (2012) Multidimensional Inventory for Religious/Spiritual Well-Being Scale (Internal consistency of $\alpha=.89$; Cronbach's $\alpha$ 's for all subscales $>0.7$ ), and Hale-Smith, Park, and Edmondson (2012) Views of Suffering Scale $(\alpha>0.7)$ have been integrated to assess religiosity related attitudes. This combination likert scale $(1=$ Strongly Disagree and $5=$ Strongly Agree) assessed participants' religious and spiritual beliefs. Some examples of questions include: "I believe there is a God or higher power," "I believe prayer has value," "I believe what happens after I die is determined by how I have lived my life." This scale was also presented to the participant before the experimental manipulations occur. 
Behavioral Temptation. Adapted from Straus' (1979) Conflict Tactics Scale this likert scale $(1=$ Not at all and $7=$ Very much so $)$ measures the participant's proclivity to hypothetically engage in specific behaviors with the other individuals who have posted on the FIU mock news blog. Some example hypothetical behaviors assessed in this scale include: Smiling at the other person, trying to make the other person laugh, humiliating them, or slapping them. Participants were told to imagine they could interact with the posters face-to-face and how tempted they would have been to engage in any of the behaviors listed in the scale. The purpose of this measure is to look at a more objective means of measuring tendencies to aggress and comparing across conditions. Cronbach's alpha for the verbal aggression and violence subscales were between .77-.88 and .62-.88 respectively (Straus, 1979).

Verbal Aggression Coding. Participants posted their thoughts, feelings, reactions, or responses to the FIU (mock) Media News Blog. Responses were coded with a yes/no ( 1 or 0$)$ for the presence of aggression anywhere in the post. For more granularity, the number of aggressive thoughts used within each post was coded as well. Posts were also be coded for the type of aggression used: Belittling/Insulting aggression is defined by any words/thoughts carrying a sense of disdain and contempt, or whose purpose is to devalue the target person (Fraser, 1981). Sarcastic aggression is any statements that indirectly express aggression through ironic criticism used to dilute condemnation or disdain (Dews and Winner, 1995; Colston, 1997). Finally, threatening aggression is any statement of intention to inflict damage, injury, or pain on an individual or group of people. Two research assistants blind to the condition underwent a brief training on coding the different types 
of aggression outlined above. The two coders were trained only on how to break up posts into number of thoughts and the types of aggression, but left to their own interpretations of how each post does or does not display aggression. A Kappa coefficient was calculated to assess the inter-coder agreement of the grand total of verbal aggression in these posts.

\section{Procedure}

Participants signed up for an individual time slot as part of the study design; a maximum of 4 students can participate during any study session. In each study session, participants were placed into separate rooms with the door closed. Each participant first completed the scale on religiosity and conservatism/liberalism then receive the anonymity manipulation questionnaire. After the anonymity manipulation, participants were exposed to the phone recording of Donald Sterling and his girlfriend. After this, participants viewed the "FIU Media News Blog" and then were asked to post on the blog about their own views or in response to other's comments. Behavioral temptation to aggress was then be assessed.

A 2 (Anonymity: Anonymous vs. Not-Anonymous) $\times 3$ (Social Modeling: Neutral/Sympathetic vs. Aggressive vs. None) between-participants design was used for this investigation. After listening to the recording, participants were told that their personal information would be revealed and available to the other people who would have access to the blog on which they are about to be posting on. However, participants assigned to be anonymous were assured that their personal information would not be revealed to anyone and were assigned a "GUEST" username. Participants were also be randomly assigned to view either neutral/sympathetic posts or aggressive posts about the 
video (sampled from actual YouTube comments with no gender, race, or age information about the author of the post included) before posting on the blog. If assigned to the third level of Social Modeling, participants viewed no posts at all and simply post on the forum themselves. In addition, there was no behavioral temptation scale given to participants who experienced no Social Modeling since the scale centers around the other posters. Finally, all participants completed the behavioral temptation scale (if applicable) and demographic questionnaire followed by a debriefing and thank you for participating in the study.

\section{Data Analysis}

To test the main effects of anonymity and social modeling on aggression, as well as the interaction of these two constructs, a 2 (Anonymous vs. Non-Anonymous) X 2 (Aggressive Modeling vs. Neutral Modeling) Analysis of Variance (ANOVA) was conducted for hypotheses 1 through 3. In this instance, the use of an ANOVA was necessary as it is highly effective in comparing means across more than 2 groups. Additionally, interaction effects and comparisons of combined effects across conditions are easily discerned with ANOVAs.

To examine the exploratory research question regarding religiosity and political affiliation's impact on these previously established links, Hayes (2009) Process method was used for testing mediation-moderation. Process uses an ordinary least squares (OLS) regression for estimating direct and indirect effects that allows for the testing of moderator and mediators while controlling for covariates (Hayes, 2009). Additionally, Process can be used to center mean scores of individual scales in order to plot changes to a dependent variable at different standard deviations of a particular score on a 
variable. For instance, political ideologies and religious/spiritual ideologies can be compared and contrasted at different standard deviation levels above and below the mean score for these variables. Taken into consideration with the interactions between the independent variables of this study, moderation and mediation of these exploratory variables can be easily illustrated using Hayes Process method. 
IV. STUDY 1 - Influence of Anonymity and Social Modeling on Aggression

\section{Preliminary Analysis}

Incomplete data due to computer malfunction before completion of the study or participants failing enter any information was removed from the analysis $(n=19)$. Prior to main analyses, various tests were performed to investigate descriptive and inferential statistics of key study variables in the study and their influence on aggression. Specifically, frequencies and descriptive statistics were run (Tables 1-13), and correlations between the key study variables were examined (Table 14). Social Modeling significantly influenced behavioral temptation to aggress, $t(549)=10.62, p>.001$, and the instance of aggressive thoughts in participant's blog posts was significantly different amongst the three modeling conditions, $F(2,720)=25.92, p>.001$. Behavioral temptation to aggress was not significantly different amongst the two anonymity conditions, $t(549)=1.307, p=.19$, nor was the number of aggressive thoughts in participant's blog posts, $t(721)=1.18, p=.24$. Behavioral temptation to aggress was positively correlated with number of aggressive thoughts on participant blog posts $(r=$ $.180, p<.001)$. Additionally, political attitudes was negatively correlated to number of aggressive thoughts in participant's blog posts $(r=-.08, p<.05)$, and religious/spiritual beliefs $(r=-.11, p<.01)$. An intra-class correlation coefficient (Kappa) was run on 60 randomly selected blog posts coded by two separate research assistants blind to the experimental conditions. The intra-class correlation was 0.77 suggesting good interrater agreement. 


\section{Analytic Procedure}

A 2 (Anonymity: Anonymity vs. No Anonymity) x 2 (Social Modeling: Aggressive vs. Neutral) Analysis of Variance (ANOVA) was conducted to evaluate the differences in total behavioral temptation amongst the 4 conditions. The analysis revealed no significant differences in mean behavioral temptation score for anonymous vs. not anonymous conditions, $F(2,551)=2.13, M S E=3.20, p=.15, \eta_{p}{ }^{2}=.004$. The analysis did reveal a significant main effect for social modeling, $F(2,551)=112.10, M S E$ $=168.73, p<.001, \eta_{p}{ }^{2}=.170$. In support of hypothesis 2 , individuals who viewed aggressive models prior to posting $(M=5.08, S D=1.18, N=285)$ scored higher on total behavioral temptation in comparison to individuals who viewed neutral models $(M=$ $3.97, S D=1.28, N=266)$.

A 2 (Anonymity: Anonymity vs. No Anonymity) x 3 (Social Modeling:

Aggressive vs. Neutral vs. No Modeling) ANOVA was conducted to assess the differences in mean number of aggressive thoughts in participant's blog posts amongst the six conditions. The analysis revealed no significant differences in number of aggressive thoughts for anonymous vs. not anonymous conditions, $F(2,723)=3.17, M S E$ $=2.11, p=.075, \eta_{p}{ }^{2}=.004$. The analysis did reveal significant differences in number of aggressive thoughts for the three social modeling conditions, $F(2,723)=24.57, M S E=$ $16.30, p>.001, \eta_{p}^{2}=.064$. Similarly, in support of hypothesis 2 , those who viewed aggressive models had a higher number of aggressive thoughts than those individuals who viewed neutral models. In addition, individuals exposed to no modeling were also more aggressive than individuals exposed to neutral modeling. However, this main effect 
was qualified by a significant interaction between the two independent variables, $F(2$, $723)=5.61, M S E=3.72, p=.004, \eta_{p}^{2}=.015$ specifying that the effects of social modeling were different for the two anonymity conditions directly supporting hypothesis 3 (see Figure 2). In anonymous participants, the number of aggressive thoughts used in blog posts was higher for individuals exposed to aggressive models $(M=0.74, S D=1.0)$ in comparison to neutral models $(M=0.23, S D=0.44)$ and those exposed to no models at all $(M=0.42, S D=0.61)$. However, for non-anonymous participants, the number of aggressive thoughts used in blog posts was highest for individuals exposed to no models $(M=0.85, S D=1.04)$ in comparison to individuals exposed to aggressive models $(M=$ $0.64, S D=0.94)$ and those exposed to neutral models $(M=0.24, S D=0.61)$. To break apart this interaction, three independent samples $t$ tests were conducted to compare the mean number of aggressive thoughts for individuals in the three modeling conditions broken up by anonymity. There were no significant differences between anonymous neutral and non-anonymous neutral conditions. There were also no significant differences between anonymous aggressive and non-anonymous aggressive conditions. There were, however, significant differences between the anonymous no modeling and non-anonymous no modeling conditions, $t(165)=3.01, p=.003$. Specifically, anonymous individuals who were exposed to no models were significantly more aggressive in comparison to not-anonymous individuals who were also exposed to no models.

\section{Discussion}

In reference to the first hypothesis, no significant main effects were found in the influence of anonymity on aggression. When looking at the anonymous vs. not 
anonymous conditions as a whole (controlling for the influences of social modeling), anonymous participants did not report significantly more behavioral temptation to aggress nor did they write more aggressive thoughts in their blog posts than those individuals who were not anonymous. When looking at mean scores of behavioral temptation to aggress, anonymous participants did have slightly higher scores (although not statistically significant) than non-anonymous participants. This trend is in line with research from Bernstein et al. (2010) and Christopherson (2006) where anonymity imbues users with the freedom to behave more aggressively without fear of social repercussion. However, this result might be slightly misleading given the intense impact of the manipulation of social modeling in this particular experiment. It is also quite possible that the impact of anonymity was not strong enough to influence participants' temptation to aggress nor their mean number of aggressive thoughts in their blog posts simply because the experimental manipulation of anonymity was not transferrable to the anonymity present in real online environments. Participants came into a psychology lab and were placed into an incommodious room very different from the safe refuge of their own home. Explicitly telling people that they are anonymous and providing them with "GUEST" usernames is not as authentic and pure as anonymity in the raw.

In line with the second hypothesis, individuals who were exposed to aggressive models were more likely to be aggressive themselves when given the opportunity to post on the mock blog as well as in the self-reported behavioral temptation scale.

Interestingly, individuals who were exposed to no modeling whatsoever wrote a similarly high number of aggressive thoughts in their posts when compared to individuals who were exposed to aggressive models. Both of these conditions were vastly different to the 
number of aggressive thoughts from individuals who were exposed to neutral models. This adds an additional layer of information about the negative behavioral consequences that exposure to aggressive models can produce (i.e., Baron, 1977; Prentice-Dunn \& Rogers, 1980) and illuminates a potential for similarly aggressive behavior when internet users are exposed to certain stimuli in the absence of any modeling cues on how to conduct themselves. Divergently, exposure to neutral/positive models seemed to inhibit the number of aggressive thoughts observed in participant's blog posts and self-reported behavioral temptation. This merges closely with literature on the modeling of positive behaviors detailed by Staub (2013). Additionally, Krebs (1970) illustrates that models make behavioral alternatives more salient and call attention to social norms on how a person might behave in a particular situation. By setting an example and providing information about what is "appropriate" or expected in a given situation, models may influence individuals to behave positively as well (Krebs, 1970). For example, White's (1972) foundational study found that children who viewed positive social modeling in the form of adults donating to a worthy cause subsequently donated more themselves when given the opportunity. Correspondingly, in a study by Rushton and Campbell (1976), adults who observed individuals donating blood were more likely to donate themselves (an effect that also carried over to blood donation 6 weeks after the experiment). These foundational studies have been replicated thoroughly (i.e., Krebs, 2015; Ottoni-Wilhelm, Estell, \& Perdue, 2014; Prot et al., 2014). The implications for positive social modeling on the internet are crucial to promoting constructive online environments where individuals can interact. 
In reference to the third hypothesis, the impact of social modeling on aggressive behavior was different in individuals who were anonymous versus those who were not anonymous. Specifically, anonymous individuals who were exposed to aggressive models wrote more aggressive thoughts in their blog posts than those individuals who were not anonymous. This echoes the research findings of Zimmerman and Ybarra (2016) where participants were most aggressive after losing a word-unscrambling game when they were both anonymous and viewed aggressive posters online. This effect was apparent in both the participant's blog posts and their self-reported behavioral temptation score (however not statistically significant in the latter measure). Interestingly, there was an opposite interaction pattern for individuals exposed to no modeling. Specifically, anonymous participants who were exposed to no modeling were less aggressive in their blog posts when compared to participants (exposed to no modeling) who were not anonymous. A possible explanation for this is that participants were doing what they thought was socially desirable when their identities were not concealed and they had no social cues on the appropriate behavioral response. Known as social desirability bias, the pervasive tendency of individuals to present themselves in the most favorable manner relative to prevailing social norms and mores has been a key concern of social science research design, and is viewed as an important factor that compromises research findings (King \& Bruner, 2000). Studies have noted that this occurs when participants respond in a way that makes them look as virtuous as possible and is a topic that has been studied extensively (Donaldson \& Grant-Vallone, 2002; Moorman \& Podsakoff, 1992). Ostensibly, the most socially desirable thing to do in this study is to be aggressive towards the individual perceived as being problematic; in this case it would be 
responding negatively to Donald Sterling due to his racist statements. To give credence to this possibility, $73.5 \%$ of participants responded in agreement to the statement "It is important to me that people do not think I am prejudiced" (agree or strongly agree), $20.1 \%$ responded with "Neutral", and only $6.4 \%$ disagreed or strongly disagreed (see Table 13). Additionally, of the 97 posts labelled as aggressive in the "No Modeling" condition, 95\% were coded as aggressive toward Donald Sterling (compared to only $79 \%$ and $59 \%$ in the aggressive and neutral modeling conditions respectively) further supporting the notion that the perceived normative response was to post aggressively against racism in the absence of alternative social models. 


\section{STUDY 2 - Political Attitudes and Religiosity/Spirituality}

\section{Analytic Procedure}

To test the exploratory hypothesis that conservative/liberal views will moderate the effect of anonymity or social modeling on aggression, a hierarchical regression (for a multi-categorical independent variable) was conducted using PROCESS (model 1) in SPSS as recommended by Hayes and Preacher (2014). When controlling for anonymity and religiosity/spirituality, political attitudes was a significant moderator of the effect of social modeling on number of aggressive thoughts in participant's blog posts, $b=0.11$, $S E=0.05, t(716)=2.81, p=.005$. Examining the plot of this interaction showed a diminishing effect on number of aggressive thoughts in individuals who scored two standard deviations above the mean on the political attitudes scale (most conservative). Individuals who scored two standard deviations below the mean in political attitudes (most liberal) tended to have more thoughts that were aggressive in their blog posts (see Figure 3).

Additionally, to probe the exploratory hypothesis that religiosity/spirituality will moderate the effect of anonymity or social modeling on aggression, another hierarchical regression (for a multi-categorical independent variable) was conducted. When controlling for anonymity and political attitudes, religiosity/spirituality was a significant moderator of the effect of social modeling on number of aggressive thoughts in participant's blog posts, $b=0.17, S E=0.07, t(715)=2.46, p=.014$. Examining the plot of this interaction showed an augmenting effect on number of aggressive thoughts in individuals who scored two standard deviations above the mean on the religiosity/spirituality scale (religious/spiritual). Individuals who scored two standard 
deviations below the mean in this scale (less religious/spiritual) tended to have fewer thoughts that were aggressive in their blog posts. However, this effect was most noticeable in the "neutral modeling" condition. (see Figure 4).

\section{Discussion}

This exploratory research question involved observing the influences of anonymity and social modeling on aggression through the lens of political attitudes and religiosity/spirituality views. The analysis of political attitudes revealed that individuals who scored lower (more liberal) in their views were more likely to be aggressive in their blog posts than individuals who scored higher (more conservative). Whereas the impact of social modeling on aggressive behavior was clearly demonstrated by this study (see hypothesis 2 and 3 ), a potent trend emerged showing that more liberal scores moderated the effects of social modeling by increasing the mean number of aggressive thoughts in blog posts throughout all conditions. This finding contradicts research on political conservatism's link to aggressive behavior (Adorno, Frenkel-Brunswik, Levinson, \& Sanford, 1950; Altemeyer, 1988; Johnson, McDermott, Cowden, \& Tingley, 2012) and instead shows a link between liberal political attitudes and aggression. This finding is likely due to the specific video footage used in the study, which shows a conservative man expressing racist and xenophobic views towards minorities. Donald Sterling expressing racist views towards minorities provokes liberals with a worldview-threat known to motivate aggression (McGregor et al., 1998). Dissimilar worldviews that threaten an individual's own worldview may provoke people to respond negatively (Greenberg, Simon, Pyszczynski, Solomon, \& Chatel, 1992). Accordingly, when faced with worldviews that conform to their own worldviews, people respond positively (Greenberg 
et al., 1992). In this particular study by Greenberg et al. (1992), participants were either primed with tolerance or not, exposed to essays from pro-US and anti-US foreign students, had mortality salience manipulated, and then evaluated the essays and the authors. While the researchers found that liberals displayed increased tolerance to mortality salience in the initial study, those primed with tolerance in the succeeding study did not show increased tolerance. Arguably, this was due to the fact that participants experienced a greater threat to their worldview in this subsequent study which stimulated them to become more focused on defense and less concerned with values of tolerance and acceptance (Greenberg et al., 1992). Similarly, this might have sparked the increase in aggressive thoughts from participants who scored lower on the political conservatism scale (more liberal). Future research could pull apart this moderation to determine if worldview threat is the culprit of the increase in aggressive behavior by testing topics that threaten or condemn conservative, in addition to, liberal ideologies.

In examination of religious/spiritual attitudes, individuals who scored higher in religiosity/spirituality were more aggressive in their blog posts across all three conditions of social modeling (aggression, neutral, and no modeling). This finding is consistent with the previously outlined literature that illustrated an increase in aggressive behavior and/or support for aggressive predilections (Grasmick, Bursik, \& Kimpel, 1991; Ellison, Bartkowski, \& Anderson, 1999). This finding contrasts literature that evidenced increases in harmonious and non-violent behavior amongst those individuals who were more religious (e.g., Koenig, 2008; Powell, 1997; Pettersson, 1991). However, a limitation of this finding is apparent - scores on religiosity/spirituality did not span very far on the 5-point Likert scale. While there was a significant increasing trend of aggressive thoughts amongst all 
conditions for individuals who scored higher on religiosity/spirituality, the practical significance is low.

However, it is more likely that religiosity and spirituality may not have the same social meanings associated with aggression or peace for these participants. Even if individuals share the same religious views and beliefs, their motivation to manage religious differences effectively are influenced by other factors (Shen, Rowatt \& LaBouff, 2012). Similarly, the actual association with religiosity and spirituality in daily life has been found to be a better indicator of violence or discrimination against others. For example, Schaller and Neuberg's (2012) study of over 190 pairs of religious groups at 97 sites around the world revealed an increase in conflict between religious groups was predicted independently and interactively by the degree to which religion was a part of a group's everyday life. Thus, it would be important to examine the actual degree to which spirituality and religion influenced an individual's daily life to better capture this identity level's influence on behavioral outcomes. 


\section{GENERAL DISCUSSION}

\section{Summary}

The goal of this study was to investigate the impact of anonymity and social modeling on online aggression in emerging adults. To reiterate the purpose of the study, there were four hypotheses discussed previously. First, emerging adults should present more online aggression when in an anonymous environment in comparison to those who are not anonymous. Second, emerging adults who view behavioral cues (posts) from aggressive models should also present more online aggression than individuals exposed to neutral models or no models at all. In effort to replicate previous research on the combined effects of anonymity and social modeling (Zimmerman \& Ybarra, 2016), emerging adults should be most aggressive when exposed to aggressive models whilst under the shroud of anonymity. In addition to measuring the influence of anonymity and social modeling on online aggression in emerging adults, this study aimed to uncover differences in the combinative effects of anonymity and social modeling when taking into account an individual's political attitudes and religiosity/spirituality. Specifically how conservative or liberal one's values are and how high they score on a religiosity/spirituality inventory.

Study 1 found no statistical evidence to support hypothesis 1 - a main effect for anonymity (when controlling for social modeling) but evidence to support the second hypothesis 2 was found - that individuals who are exposed to aggressive models will behave more aggressively than individuals exposed to neutral/positive models. This was qualified by an interaction effect of anonymity and social modeling, as predicted in 
hypothesis 3. Specifically, anonymous individuals were most aggressive when exposed to aggressive models in comparison to neutral/positive models or none at all.

Contrastingly, non-anonymous individuals who were told their identities would be revealed were most aggressive when they were exposed to no models. Non-anonymous individuals who were exposed to aggressive models still displayed more aggression in their blog posts than those who were exposed to neutral/positive models. However, they displayed less aggressive thoughts in their posts when compared to individuals who were exposed to no models at all.

\section{Limitations}

This dissertation greatly supplements the large body of literature on anonymity, and social modeling, and successfully unites these constructs to explain online aggression in emerging adults. However, several limitations should be noted regarding the scope of this study. One obvious shortcoming of this research is in the very design of anonymity and how to accurately measure it in the laboratory setting. This study did find evidence for an interaction between the anonymity and social modeling conditions; however, when controlling for other variables, anonymity was not a significant predictor of behavioral temptation to aggress or aggressive thoughts on participant's posts. Participants signed up for this study through a web-based system that uses their university log-in information, they came into an incommodious room very different from the comfort of their own home, and they likely felt that they were being observed (as is typical when completing a psychological experiment). Future attempts to study anonymity might consider comparing these findings to natural observations of behavior in anonymous virtual environments. 
Similarly, another measurement limitation that should be addressed is the lack of ability to assess direct influences. The measures utilized may not be indicative of the experience of the realities of the study's sample and may not be capturing the influence of religion, spiritually and political role beliefs specifically. The current study's findings highlight the necessity of updating and refining measures that can better illustrate the role of these influential belief systems direct influences on online aggression behaviors. Furthermore, measurement refinement needs to address the unique experiences and within-group differences of diverse college men and women.

Finally, the stimulus used- the Donald Sterling incident- may have different meanings to different individuals based upon their religion, spiritually and political role beliefs. Participants may have not drawn upon religion/spirituality or political beliefs when considering this stimulus. Rather, their beliefs about age, race/ethnicity, gender or social class may have been a better indicator for assessing online aggression. Similarly, Donald Sterling's age, the situation under which he was recorded, and his social status may have shaped participants perceptions differently than a stimulus about an individual or situation that directly affects their own identity. A stimulus that was specific to individuals of this age group and region may better capture understandings about online aggression.

Additionally, it should be noted that college students in the age period of emerging adulthood are a unique population and might not be comparable to other age groups (Arnett, 2008; Bynner, 2005). Most obviously, they are at a stage of development where they have greater independence in their ability to express themselves and their beliefs (Arnett, 2004). When looking at their actual engagement 
in online environments, there are clear differences, that include the fact their internet usage is significantly higher (Greenwood, Perrin, \& Duggan, 2016), and they tend to utilize social media for communications and self-expression in different ways (Brown, 2006; Cicchirillo, Hmielowski, \& Hutchens, 2015; Griffiths et al., 2017). Further, their ability to control their usage of social media differs from adolescents or young adults that may still depend upon parents to monitor, pay for, or access their activities (Lenhart, 2009). Thus the results of this study may not be exclusively applicable of all different populations or age groups. The constructs that influenced online aggression of emerging adults in this study might guide online behavior of other groups in a different manner.

\section{Strengths and Significance}

In spite of the limitations outlined in the previous section, this dissertation greatly contributes to the body of literature on anonymity, social modeling, and online aggression. While anonymous environments clearly imbue users with a sense of freedom and autonomy to engage in uncharacteristic and potentially aggressive behaviors (Eastwick \& Gardner, 2009; Yee, 2006) it is important to recognize that online behavior is heterogeneous and multi-determined (Billieux et al., 2015). Specifically, this study's inclusion of the social modeling construct revealed just how strongly individuals are influenced by exposure to aggressive or positive/neutral models and how this differs from their behavior in the absence of models altogether. When individuals were exposed to aggressive posts, they were more likely to self-report aggressive behavioral temptations, and were more likely to contribute a higher mean number of aggressive thoughts to the mock public forum. This effect overpowered the influence of anonymity for both 
measures of subjective behavioral temptation and objective aggressive thoughts in participant's blog posts. Additionally, the inclusion of a condition that removed modeling altogether added an extra layer that detailed a unique interaction with anonymity for aggressive thoughts on the mock public forum. Anonymous individuals who were exposed to no models typed less aggressive posts than those who were exposed to aggressive models, but were more aggressive than individuals who were exposed to neutral/positive models. This suggests that the presence (or absence) of behavioral cues does matter in the exhibition of emerging adult's subsequent behavior. However, individuals who were not anonymous and exposed to no models were most aggressive in comparison to the other conditions suggesting that in the absence of behavioral cues participant's ideas of social desirability may come into play.

Furthermore, this study found evidence for the moderating effect of political attitudes and religious/spiritual beliefs on online aggression. Individuals who scored lower in the political attitudes scale (more liberal) were more aggressive in their subsequent blog posts. However, it should be noted that the implication of higher liberal scores leading to increases in aggressive behavior could be distorted. The stimulus used in this study was a video of an overtly racist elderly male, Donald Sterling, which arguably poses a threat to a liberal worldview. Liberalism is frequently associated with values of tolerance and acceptance of others and cogently should decrease aggression; however, threats to one's worldview increase concern with defense and promote aggressive responses (Greenberg et al., 1992; McGregor et al., 1998). Individuals with conservative ideologies typically prefer aggressive actions towards outgroups (Holsti, 
1996; McCann, 2008) but arguably would respond less aggressively towards individuals that confirm or support worldviews similar to their own.

As mentioned previously, emerging adults strive for autonomy and the internet provides the perfect medium for behavioral experimentation and has a tremendous impact on other people from around the world. Emerging adults are working to solidify world views, morals, values, and political/religious affiliations and are pointedly different from other individuals at different stages of the lifespan. That, coupled with their unparalleled internet use (Pew Research Center, 2015), make emerging adults an important and influential population for inquiry into their online behaviors.

\section{Conclusions}

Given that online environments have only emerged as normative spaces in the past two decades, it is important to identify the ways in which the current cohort of emerging adults have been utilizing these unique tools for communication and selfexpression, while exploring factors that shape their behavioral outcomes. It is particularly important to explore this phenomenon as emerging adults' social media usage and engagement is on the rise, even surpassing usage among adolescents and young adults (Greenwood, Perrin, \& Duggan, 2016). This dissertation specifically lays out a foundational framework for identifying the contributing factors of online aggression, an important area of study as cyberbullying online is found to be high among young and emerging adults (Kann et al., 2013), and directly affects psychological well-being (Finkelhor et al., 2000).

Further, these findings not only illuminate the conditions that encourage aggressive behavior online, but also contribute two additional important moderators to 
the literature - liberal/conservative political attitudes and religious/spiritual beliefs (or lack thereof). Given that emerging adulthood is the period when these two value and belief systems become more salient, they are important to explore as influencing online communications (Cooper, 2014; Snell, 2010). More exploration is needed to determine the true influence of political and religious attitudes on online aggression or if these moderators can be clarified with research on worldview threat. Specifically, while it is logical to assume that liberals generally respond with greater tolerance and acceptance in comparison to individuals who hold more conservative political ideologies (Johnson, McDermott, Cowden, \& Tingley, 2012), this dissertation found contradictory evidence of increased aggression among more liberal individuals. Studying defensive, and sometimes aggressive, responses that result with threats to one's worldview (Greenberg et al., 1992; McGregor et al., 1998) would help shed light on how emerging adults are impacted by this construct.

Important starting points for future areas of research are also highlighted by this dissertation's findings. Deeper exploration of other moderating variables is crucial to a comprehensive understanding of online aggression. For example, Prot et al. (2014) found that empathy was a mediator of the effects of prosocial video game behavior and prosocial media on individuals' subsequent behavior. Other studies that focus on personality characteristics and emotional regulation as moderators in cyber aggression (Kokkinos \& Voulgaridou, 2017) are vital in understanding factors that may predict when (or to what degree) individuals might engage in aggressive behaviors in online environments. Other states like loneliness (previously discussed) can also impact which venues of online interaction an individual might seek out as well as the positive or 
negative behaviors that might result from being in that particular state (Morahan-Martin $\&$ Schumacher, 2003).

Future research should also focus on the application of these research findings in developing methods to increase positive behaviors in online environments. While a common strategy for eliminating online aggression is to publicly identify internet users in communication environments (Millen \& Patterson, 2003), online behavior is heterogeneous and multi-determined (Billieux et al., 2015). It is important to recognize that cyber-bullying, trolling, and flaming are not only found in anonymous environments, but on social media outlets like Facebook and Twitter (Patton et al., 2014) where names and identities of posters are publicly available to other users. This research shows the complexity of online aggression and the importance of measuring multiple variables to gain a better understanding of online aggression. This kind of research focus is particularly important given that the internet has become an essential part of many individual's lives, and users not only engage in social media and gaming environments, but also look for support structures to discuss social/personal and health issues (Fox \& Duggan, 2013). In many of these environments, anonymity and social modeling are crucial components that govern and guide behavior and allow individuals to feel comfortable expressing their emotions, concerns, and opinions publicly. Investigations of other online environments where help-seeking traffic is common and the incorporation of open access internet support forums that are moderated would contribute to our understandings about behaviors across genres (Griffiths, Carron-Arthur, Reynolds, Bennett, \& Bennett 2017; McKiernan, Ryan, McMahon, \& Butler, 2017). Further, this 
kind of empirical examination will enhance efforts seeking to promote positive online atmospheres for users to safely disclose personal information and express their emotions. 
Figure 1. Mean behavioral temptation score by anonymity and social modeling.

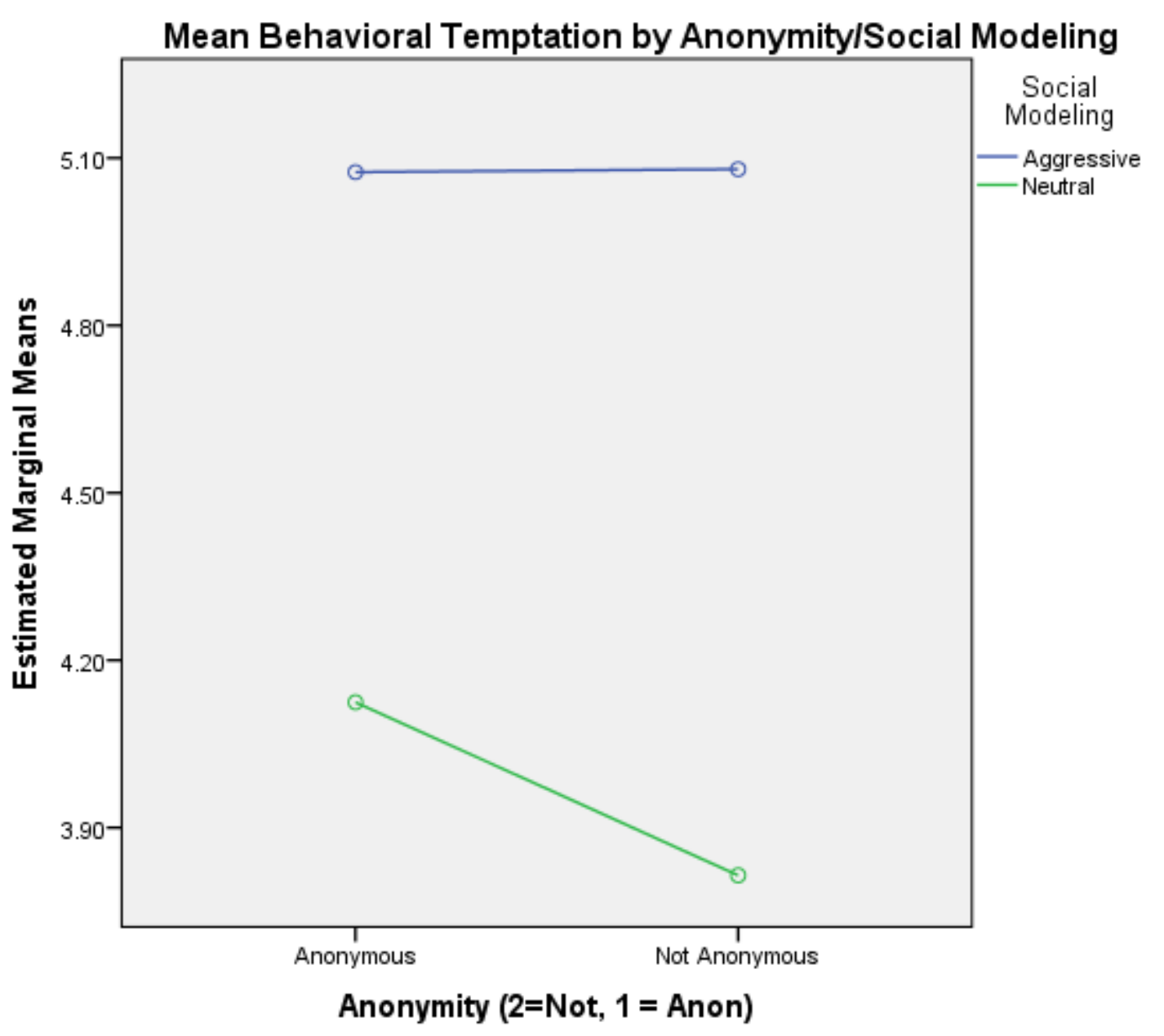


Figure 2. Mean number of aggressive thoughts by anonymity and social modeling.

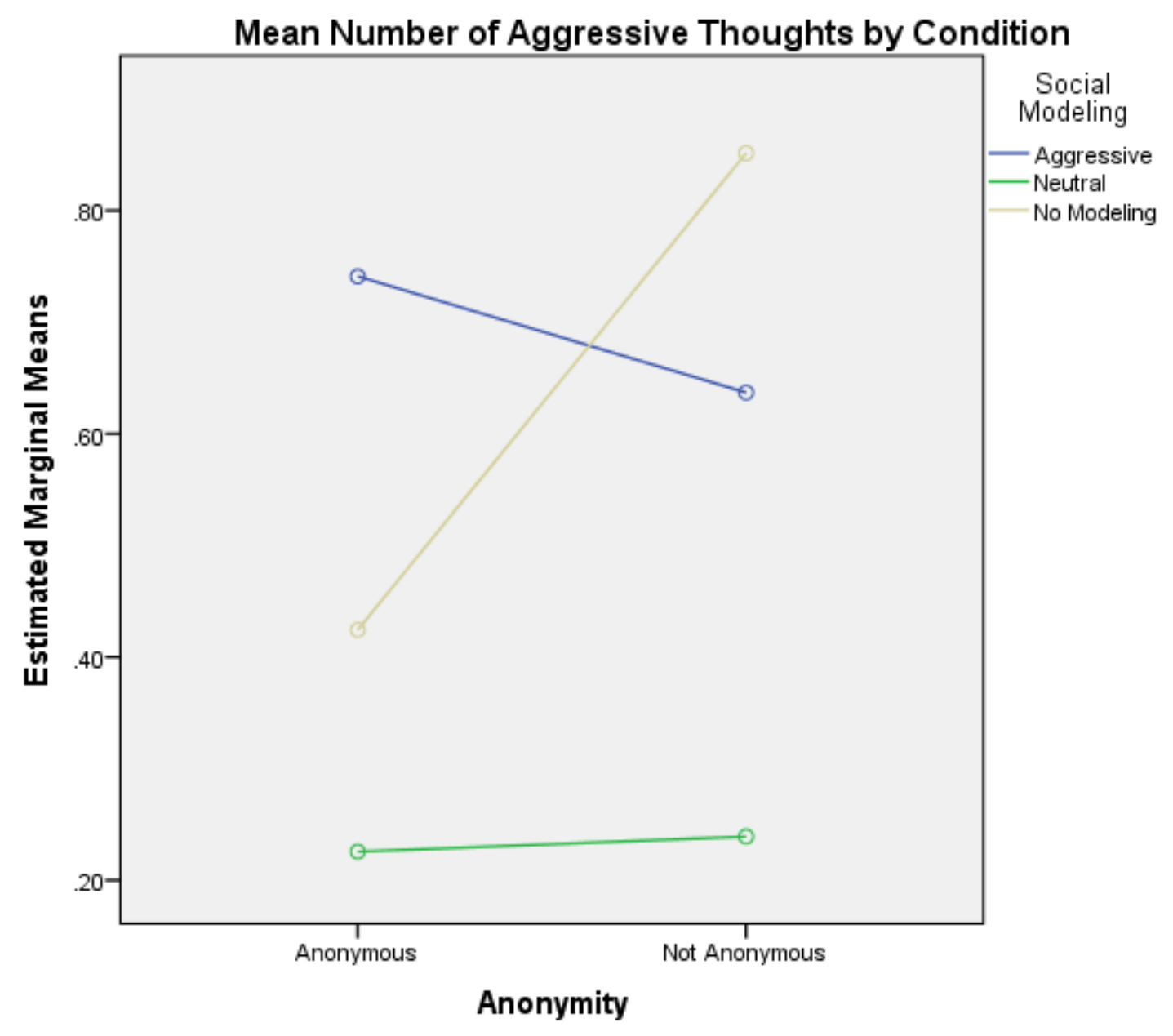


Figure 3. Centered means of political attitudes by 3 social modeling conditions.

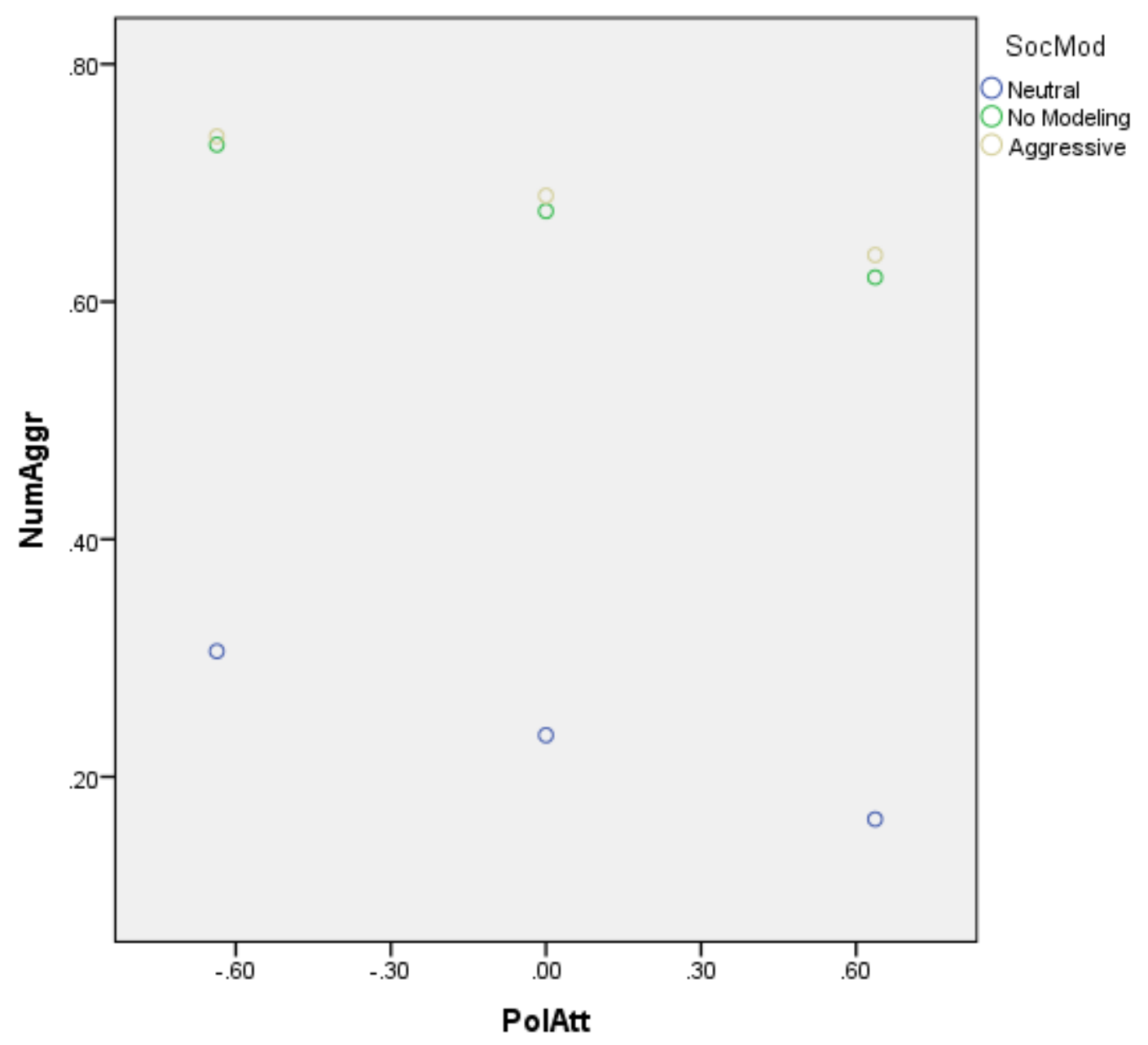


Figure 4. Centered means of religiosity/spirituality by 3 social modeling conditions

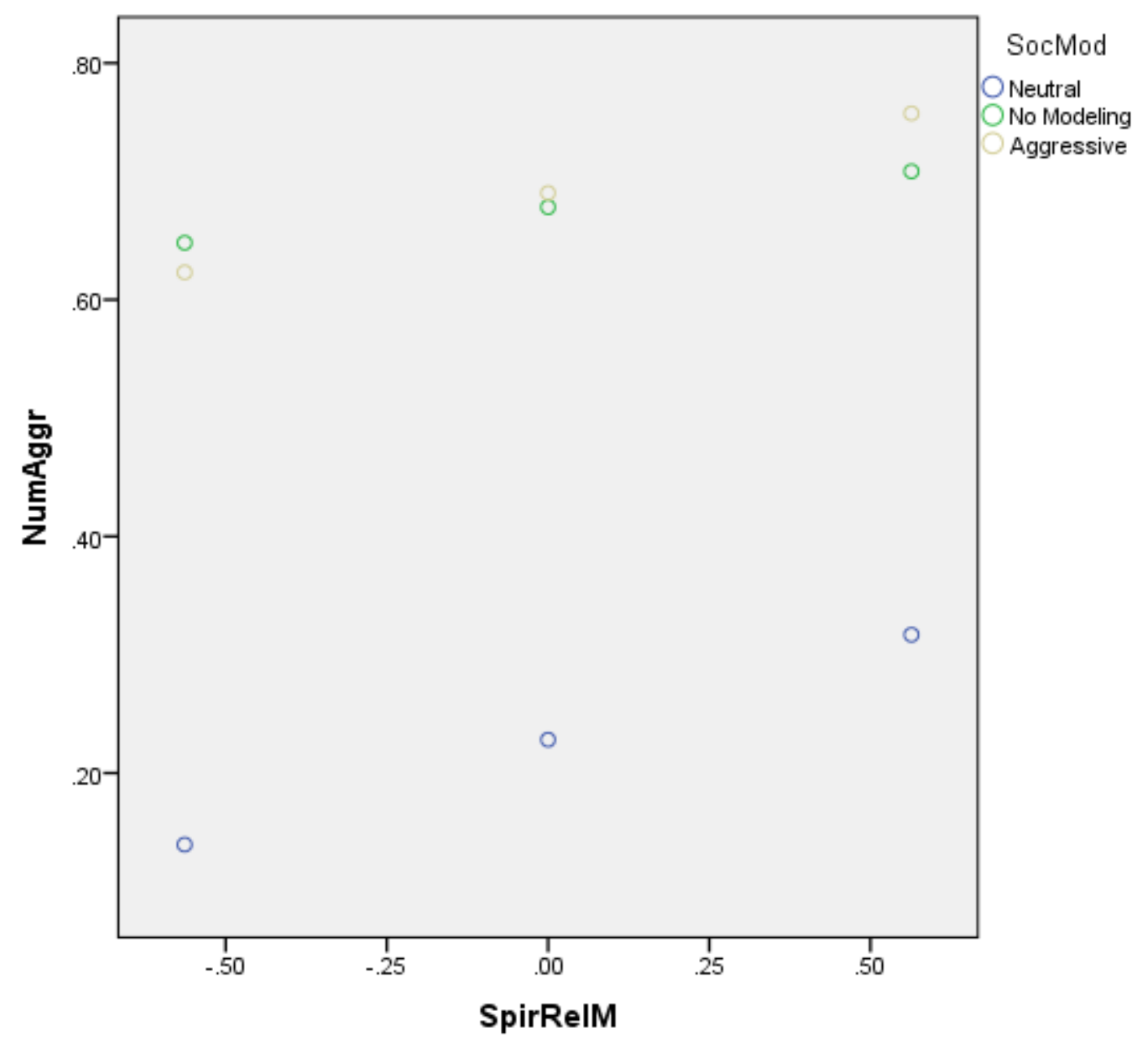




\section{TABLES}

Table 1

Family Nation of Origin

\begin{tabular}{|c|c|c|}
\hline & Frequency & Percent \\
\hline Africa & 8 & 1.1 \\
\hline Argentina & 5 & .7 \\
\hline Australia & 1 & .1 \\
\hline Bahamas & 5 & .7 \\
\hline Bangladesh & 1 & .1 \\
\hline Barbados & 1 & .1 \\
\hline Bermuda & 1 & .1 \\
\hline Bolivia & 3 & .4 \\
\hline Brazil & 8 & 1.1 \\
\hline Bulgaria & 1 & .1 \\
\hline Canada & 2 & .3 \\
\hline Cayman Islands & 2 & .3 \\
\hline Chile & 3 & .4 \\
\hline China & 2 & .3 \\
\hline Colombia & 54 & 7.5 \\
\hline Congo & 1 & .1 \\
\hline Cuba & 169 & 23.4 \\
\hline Curacao & 1 & .1 \\
\hline Dominica & 1 & .1 \\
\hline Dominican Republic & 22 & 3.0 \\
\hline Earth & 1 & .1 \\
\hline Ecuador & 6 & .8 \\
\hline Egypt & 1 & .1 \\
\hline El Salvador & 3 & .4 \\
\hline England & 1 & .1 \\
\hline Europe & 2 & .3 \\
\hline France & 3 & .4 \\
\hline German & 1 & .1 \\
\hline Germany & 5 & .7 \\
\hline Greece & 2 & .3 \\
\hline Guatemala & 2 & .3 \\
\hline
\end{tabular}




\begin{tabular}{|c|c|c|}
\hline Guyana & 3 & .4 \\
\hline Haiti & 41 & 5.7 \\
\hline Honduras & 8 & 1.1 \\
\hline India & 12 & 1.7 \\
\hline Iran & 1 & .1 \\
\hline Ireland & 3 & .4 \\
\hline Israel & 3 & .4 \\
\hline Italy & 7 & 1.0 \\
\hline Jamaica & 29 & 4.0 \\
\hline Korea & 1 & .1 \\
\hline Lebanon & 3 & .4 \\
\hline Mexico & 11 & 1.5 \\
\hline Miami & 4 & .6 \\
\hline Morocco & 1 & .1 \\
\hline N/A & 19 & 2.6 \\
\hline Netherlands & 1 & .1 \\
\hline Nicaragua & 25 & 3.5 \\
\hline Nigeria & 3 & .4 \\
\hline Pakistan & 7 & 1.0 \\
\hline Palau & 1 & .1 \\
\hline Panama & 4 & .6 \\
\hline Peru & 17 & 2.4 \\
\hline Philippines & 1 & .1 \\
\hline Poland & 4 & .6 \\
\hline Portugal & 1 & .1 \\
\hline Puerto Rico & 15 & 2.1 \\
\hline Romania & 1 & .1 \\
\hline Russia & 3 & .4 \\
\hline Saudi Arabia & 9 & 1.2 \\
\hline Spain & 9 & 1.2 \\
\hline St. Maarten & 1 & .1 \\
\hline Trinidad & 6 & .8 \\
\hline Turkey & 1 & .1 \\
\hline United States & 119 & 16.5 \\
\hline Venezuela & 28 & 3.9 \\
\hline Vietnam & 2 & .3 \\
\hline Total & 723 & 100.0 \\
\hline
\end{tabular}


Table 2

Primary Racial Identity

\begin{tabular}{lcc}
\hline & Frequency & Percent \\
\hline Asian & 36 & 5.0 \\
Black/African Descent & 140 & 19.4 \\
Hispanic/Latin American & 414 & 57.3 \\
Indigenous/Native & 3 & .4 \\
White non-Hispanic/Caucasian & 95 & 13.1 \\
Other & 35 & 4.8 \\
Total & 723 & 100.0 \\
\hline
\end{tabular}

Note. Due to rounding, these percentages may not add up to $100 \%$. 
Table 3

\begin{tabular}{|c|c|c|}
\hline & Frequency & Percent \\
\hline Not Applicable & 306 & 42.3 \\
\hline Asian & 13 & 1.8 \\
\hline Black/African Descent & 48 & 6.6 \\
\hline Hispanic/Latin American & 170 & 23.5 \\
\hline Indigenous/Native & 6 & .8 \\
\hline White non-Hispanic/Caucasian & 125 & 17.3 \\
\hline Other & 55 & 7.6 \\
\hline Total & 723 & 100.0 \\
\hline
\end{tabular}

Note. Due to rounding, these percentages may not add up to $100 \%$. 
Table 4

Sex

\begin{tabular}{lcc}
\hline & Frequency & Percent \\
\hline Male & 311 & 43.0 \\
Female & 412 & 57.0 \\
Total & 723 & 100.0 \\
\hline
\end{tabular}

Note. Due to rounding, these percentages may not add up to $100 \%$. 
Table 5

Highest Education Level (Mother)

\begin{tabular}{lcc}
\hline & Frequency & Percent \\
\hline Some elementary school & 7 & 1.0 \\
Elementary school & 7 & 1.0 \\
Some high school & 33 & 4.6 \\
High school & 140 & 19.4 \\
Some college & 145 & 20.1 \\
Associate's degree & 112 & 15.5 \\
Bachelor's degree & 156 & 21.6 \\
Some graduate school & 14 & 1.9 \\
Masters level degree & 83 & 11.5 \\
Doctoral level degree & 26 & 3.6 \\
Total & 723 & 100.0 \\
\hline
\end{tabular}

Note. Due to rounding, these percentages may not add up to $100 \%$. 
Table 6

Highest Education Level (Father)

\begin{tabular}{lcc}
\hline & Frequency & Percent \\
\hline Some elementary school & 6 & .8 \\
Elementary school & 9 & 1.2 \\
Some high school & 52 & 7.2 \\
High school & 180 & 24.9 \\
Some college & 128 & 17.7 \\
Associate's degree & 50 & 6.9 \\
Bachelor's degree & 160 & 22.1 \\
Some graduate school & 14 & 1.9 \\
Masters level degree & 84 & 11.6 \\
Doctoral level degree & 40 & 5.5 \\
Total & 723 & 100.0 \\
\hline
\end{tabular}

Note. Due to rounding, these percentages may not add up to $100 \%$. 
Table 7

\begin{tabular}{lcc} 
Current Relationship Status & \\
\hline & Frequency & Percent \\
\hline Single not dating & 279 & 38.6 \\
Single dating casually & 150 & 20.7 \\
In a relationship (Less than 6 months) & 49 & 6.8 \\
In a relationship (Less than 2 years) & 85 & 11.8 \\
In a relationship (2 years or longer) & 114 & 15.8 \\
Engaged & 14 & 1.9 \\
Married/formal commitment & 32 & 4.4 \\
Total & 723 & 100.0 \\
\hline
\end{tabular}

Note. Due to rounding, these percentages may not add up to $100 \%$. 
Table 8

Preferred Sexual Partners

\begin{tabular}{llcc}
\hline & & Frequency & Percent \\
\hline Valid & Males & 399 & 55.2 \\
& Females & 301 & 41.6 \\
& Both & 23 & 3.2 \\
& Total & 723 & 100.0 \\
\hline
\end{tabular}

Note. Due to rounding, these percentages may not add up to $100 \%$. 
Table 9

Class Standing

\begin{tabular}{lcc}
\hline & Frequency & Percent \\
\hline Freshman & 202 & 27.9 \\
Sophomore & 107 & 14.8 \\
Junior & 213 & 29.5 \\
Senior & 169 & 23.4 \\
Grad Student & 3 & .4 \\
Other & 29 & 4.0 \\
Total & 723 & 100.0 \\
\hline
\end{tabular}

Note. Due to rounding, these percentages may not add up to $100 \%$. 
Table 10

Religious/Spiritual Views

\begin{tabular}{lcc}
\hline & Frequency & Percent \\
\hline At least once in my life I have had an intense spiritual experience & \\
Strongly Disagree & 80 & 11.1 \\
Disagree & 126 & 17.4 \\
Neither Agree nor Disagree & 169 & 23.4 \\
Agree & 183 & 25.3 \\
Strongly Agree & 164 & 22.7
\end{tabular}

Our flawed and often horrific behavior indicated that there is little or no meaning inherent in our existence

Strongly Disagree

150

20.7

Disagree

214

29.6

Neither Agree nor Disagree

264

36.5

Strongly Agree

65

9.0

Strongly Disagree

30

4.1

I see a special purpose for myself in this world

Strongly Disagree

Disagree

Neither Agree nor Disagree

132

18.3

Agree

269

37.2

Strongly Agree

261

36.1

I believe in further existence after death

Strongly Disagree

Disagree

Neither Agree nor Disagree

Agree

Strongly Agree

Although I cannot always understand, I believe everything happens for a reason

Strongly Disagree 35

Disagree

Neither Agree nor Disagree

Agree

Strongly Agree

I am a religious person

Strongly Disagree

Disagree

Neither Agree nor Disagree

Agree

Strongly Agree 
Religious ceremonies are important to me

Strongly Disagree $\quad 121$

Disagree

Neither Agree nor Disagree

Agree

Strongly Agree

I believe prayer has value

Strongly Disagree

Disagree

Neither Agree nor Disagree

Agree

Strongly Agree

I believe there is a God or higher power

Strongly Disagree 46

6.4

Disagree

Neither Agree nor Disagree

I feel the presence of God or a higher power in nature

Strongly Disagree

Disagree

Neither Agree nor Disagree

Strongly Agree

My faith gives me a feeling of security

Strongly Disagree

Disagree

Neither Agree nor Disagree

Strongly Agree

I have never had a spiritual bond with anyone

Strongly Disagree

Disagree

Neither Agree nor Disagree

Agree

Strongly Agree

In certain moments in my life, I feel very close to a God or a higher power

Strongly Disagree

Disagree

Neither Agree nor Disagree

Agree

Strongly Agree
74

69

10.2

9.5

146

220

212
30.4

29.3
20.2 
Table 11

Political Attitudes/Beliefs

Frequency

Percent

The majority of those who criticize proper authorities in government and religion only create useless doubts in people's minds

$\begin{array}{lcc}\text { Strongly Disagree } & 82 & 11.3 \\ \text { Disagree } & 153 & 21.2 \\ \text { Neither Agree nor Disagree } & 165 & 22.8 \\ \text { Agree } & 179 & 24.8 \\ \text { Strongly Agree } & 100 & 13.8\end{array}$

What our country really needs instead of more "civil rights" is a good stiff dose of law and order

$\begin{array}{lcc}\text { Strongly Disagree } & 120 & 16.6 \\ \text { Disagree } & 182 & 25.2 \\ \text { Neither Agree nor Disagree } & 169 & 23.4 \\ \text { Strongly Agree } & 163 & 22.5 \\ \text { Strongly Disagree } & 57 & 7.9\end{array}$

What our country really needs is a strong, determined leader who will crush evil, and take us back to our true path

Strongly Disagree

93

Disagree

113

15.6

Neither Agree nor Disagree

168

23.2

Agree

205

28.4

Strongly Agree

87

12.0

People can have more than one attitude or belief and it won't necessarily fall under one political affiliation (i.e., Democrat, Republican, etc.)

Strongly Disagree 6

Disagree 10

.8

Neither Agree nor Disagree

32

1.4

Agree

141

4.4

Strongly Agree

293

19.5

We should help disadvantaged groups secure equal rights

Strongly Disagree 4

Disagree

4
7

40.5

Neither Agree nor Disagree

30

.6

Agree

98

4.1

Strongly Agree

254

13.6

35.1

Note. Due to rounding, these percentages may not add up to $100 \%$. 
Table 12

\begin{tabular}{ccc} 
Number of Aggressive Thoughts in Post & \\
\hline & Frequency & Percent \\
\hline .00 & 464 & 64.2 \\
1.00 & 184 & 25.4 \\
2.00 & 48 & 6.6 \\
3.00 & 18 & 2.5 \\
4.00 & 7 & 1.0 \\
5.00 & 1 & .1 \\
6.00 & 1 & .1 \\
Total & 723 & 100.0 \\
\hline
\end{tabular}

Note. Due to rounding, these percentages may not add up to $100 \%$. 
Table 13

It is important to me that people do not think I am prejudiced

Frequency

Percent

$\begin{array}{lcc}\text { Agree or Strongly Agree } & 528 & 73.5 \\ \text { Neutral } & 146 & 20.1 \\ \text { Disagree or Strongly Disagree } & 45 & 6.4\end{array}$

Note. Due to rounding, these percentages may not add up to $100 \%$. 
Table 14

Correlations

\begin{tabular}{|c|c|c|c|c|c|c|}
\hline & & $\begin{array}{c}\text { Number of } \\
\text { Aggressive } \\
\text { Thoughts }\end{array}$ & $\begin{array}{l}\text { Spirituality } \\
\text { Religiosity }\end{array}$ & $\begin{array}{l}\text { Political } \\
\text { Attitudes }\end{array}$ & $\begin{array}{l}\text { Behavioral } \\
\text { Temptation }\end{array}$ & Sex \\
\hline Number & Pearson & 1 & -.011 & $-.074^{*}$ & $.180^{* *}$ & $.074^{*}$ \\
\hline \multicolumn{7}{|c|}{ Aggressive Correlation } \\
\hline \multirow[t]{2}{*}{ Thoughts } & Sig. (2-tailed) & & .772 & .047 & .000 & .047 \\
\hline & $\mathrm{N}$ & 723 & 723 & 723 & 551 & 723 \\
\hline Spirituality & Pearson & -.011 & 1 & $-.113^{* *}$ & .008 & - \\
\hline /Religiosit & Correlation & & & & & $.117^{* *}$ \\
\hline \multirow[t]{2}{*}{$\mathrm{y}$} & Sig. (2-tailed) & .772 & & .002 & .858 & .002 \\
\hline & $\mathrm{N}$ & 723 & 723 & 723 & 551 & 723 \\
\hline \multirow{4}{*}{$\begin{array}{l}\text { Political } \\
\text { Attitudes }\end{array}$} & Pearson & $-.074^{*}$ & - & 1 & -.054 & .040 \\
\hline & Correlation & & $.113^{* *}$ & & & \\
\hline & Sig. (2-tailed) & .047 & .002 & & .203 & .281 \\
\hline & $\mathrm{N}$ & 723 & 723 & 723 & 551 & 723 \\
\hline \multirow{4}{*}{$\begin{array}{l}\text { Behavioral } \\
\text { Temptatio } \\
\mathrm{n}\end{array}$} & Pearson & $.180^{* *}$ & .008 & -.054 & 1 & .081 \\
\hline & Correlation & & & & & \\
\hline & Sig. (2-tailed) & .000 & .858 & .203 & & .058 \\
\hline & $\mathrm{N}$ & 551 & 551 & 551 & 551 & 551 \\
\hline \multirow[t]{4}{*}{ Sex } & Pearson & $.074^{*}$ & - & .040 & .081 & 1 \\
\hline & Correlation & & $.117^{* *}$ & & & \\
\hline & Sig. (2-tailed) & .047 & .002 & .281 & .058 & \\
\hline & $\mathrm{N}$ & 723 & 723 & 723 & 551 & 723 \\
\hline
\end{tabular}

*. Correlation is significant at the 0.05 level (2-tailed).

**. Correlation is significant at the 0.01 level (2-tailed). 


\section{REFERENCES}

Adorno, T. W., Frenkel-Brunswik, E., Levinson, D. J., \& Sanford, R. N. (1950). New York: Harper and Row.

Aiken, L. A., \& West, S. G. (1991). Multiple regression: Testing and interpreting interactions. Newbury Park, CA: Sage.

Altemeyer, B. (1988). Enemies of freedom: Understanding right-wing authoritarianism. San Francisco: Jossey-Bass.

Apollo, A. M. (2007). Cyberbullying: Taking the fight online. Retrieved February 20, 2007, from http://saferschools.blogspot.com/2007/02/october-9-2005-bonitabanner.html

Arbuckle, J. L. (2006). Amos (Version 21.0) [Computer Program]. Chicago, IL: SPSS.

Arnett, J. J. (2004). Emerging adulthood: The winding road from the late teens through the twenties Oxford University Press.

Arnett, J., Ramos, K., \& Jensen, L. (2001). Ideological Views in Emerging Adulthood: Balancing Autonomy and Community. Journal of Adult Development, 8, 69-79.

Bandura, A., Ross, D., \& Ross, S. A. (1961). Transmission of aggression through imitation of aggressive models. The Journal Of Abnormal And Social Psychology, 63, 575-582. doi:10.1037/h0045925

Bandura, A. (1997). Self-efficacy: The exercise of control. New York: Freeman.

Baron, R. A. Human aggression. New York: Plenum Press, 1977.

Barry, M. C., Nelson, L. (2005). The role of religion in the transition to adulthood for young emerging adults. Journal of Youth and Adolescence 34, 245-255. doi: 10.1007/s10964-005-4308-1.

Barry, M. C., Nelson, L., Davarya, S., \& Urry, S. (2010). Religiosity and spirituality during the transition to adulthood. International Journal of Behavioral Development. 34, 311-324. doi:10.1177/0165025409350964.

Baumgartner, S. E., Valkenburg, P. M. \& Peter, J. (2010). Unwanted online sexual solicitation and risky sexual online behavior across the lifespan. Journal of Applied Developmental Psychology, 31, 439- 447. 
Bernstein, M. S., A. Monroy-Hernández, D. Harry, P. André, K. Panovich, \& Vargas, G. (2011). 4chan and /b/: An analysis of anonymity and ephemerality in a large online community. In Proceedings of the Fifth International AAAI Conference on Weblogs and Social Media, Barcelona, Spain. AAAI Press.

Billieux, J., Thorens, G., Khazaal, Y., Zullino, D., Achab, S., \& Van der Linden, M. (2015). Problematic involvement in online games: A cluster analytic approach. Computers in Human Behavior, 43, 242-250.

Boyd, D. (2010). "for the lolz": 4chan is hacking the attention economy. http://www.zephoria. org / thoughts/archives/2010/06/12/for-the-lolz-4chan-ishacking-the-attention-economy.html.

Brown, J. D. (2006). Emerging adults in a media-saturated world. In: Emerging Adults in America: Coming of age in the $21^{\text {st }}$ century. J. J. Arnett \& J.L. Tanner (Eds.); Washington, DC, US: American Psychological Association, 279-299.

Bynner, J. (2005). Rethinking the Youth Phase of the Life-course: The Case for Emerging Adulthood? Journal of Youth Studies, 8, 367- 384.

Cicchirillo, V., Hmielowski, J., \& Hutchens, M. (2015). The mainstreaming of verbally aggressive online political behaviors. Cyberpsychology, Behavior, and Social Networking, 18, doi:10.1089/cyber.2014.0355.

Christopherson, K. M. (2007). The positive and negative implications of anonymity in Internet social interactions: "On the Internet, Nobody Knows You're a Dog." Computers in Human Behavior, 23(6), 3038-3056. doi:10.1016/j.chb.2006.09.001.

Colston, H. L., (1997). Salting a wound or sugaring a pill: The pragmatic functions of ironic criticism. Discourse Processes, 23, 25-45.

Cooper, L. (2013). The relationship between television viewing and the political knowledge and behaviors of the emerging adults (Doctoral Dissertation). Retrieved from ProQuest Database.

Diener, E., Dineen, J., Endresen, K., Beaman, A. L., \& Fraser, S. C., (1975) Effects of altered responsibility, cognitive set, and modeling on physical aggression and deindividuation. Journal of Personality and Social Psychology, 31, 328-337.

Dews, S., Kaplan, J., \& Winner, E. (1995). Why not say it directly? The social functions of irony. Discourse Processes, 19, 347-367. 
Donaldson, S., \& Grant-Vallone, E. (2002). Understanding Self-Report Bias in Organizational Behavior Research. Journal of Business and Psychology, 17(2), 245-260. Retrieved from http://www.jstor.org/stable/25092818.

Eastwick, P.W., \& Gardner, L. W. (2009). Is it a game? Evidence for social influence in the virtual world. Social Influence, 4, 18-32.

Ellison, T. D., Barkowski, J. P., \& Anderson, K. L. (1999). Are there religious variations in domestic violence? Journal of Family Issues, 20, 87-113.

Finkelhor, D., Mitchell, K., \& Wolak, J. (2000b). Online victimization: A report on the nation's youth. National Center for Missing \& Exploited Children. Retrieved November 2, 2015 from http://www.unh.edu/ccrc/ Youth_Internet_info_page.html

Fox, S., \& Duggan, M. (2013). Health online 2013 Pew Research Center's internet and American life project. Washington, DC: Pew Research Center.

Frable, D. E. S., (1993). Being and feeling unique: Statistical deviance and psychological marginality. Journal of Personality, 61, 85-110.

Fraser, B. (1981). Insulting problems in a second language. TESOL Quarterly, 15, 435441.

Grasmick, H. G., Bursik, R. J., \& Kimpel, M. (1991). Protestant fundamentalism and attitudes toward corporal punishment for children. Violence Vict, 6, 283-298.

Greenberg, J., Simon, L., Pyszczynski, T., Solomon, S., \& Chatel, D. (1992). Terror management and tolerance: Does mortality salience always intensify negative reactions to others who threaten one's worldview? Journal of personality and social psychology, 63(2), 212.

Greenwood, S., Perrin, A., \& Duggan, M. (2016) Social Media Update 2016. Pew Research Center's Social Media Update 2016. Washington, DC. Retrieved April 1, 2017 from http://www.pewinternet.org/2016/11/11/social-media-update-2016/.

Griffiths, K. M., Carron-Arthur, B., Reynolds, J., Bennett, K., \& Bennett, A. (2017). User characteristics and usage of an open access moderated internet support group for depression and other mental disorders: A prospective study. Internet Interventions, 7, 9-15.

Hale-Smith, A., Park, C. L., \& Edmondson, D. (2012). Views of Suffering Scale [Database record]. Retrieved from PsycTESTS. doi: 10.1037/t14551-000. 
Haney, C., Banks, W. C., \& Zimbardo, P. G. (1973). Interpersonal dynamics in a simulated prison. International Journal of Criminology and Penology, 1, 69-97.

Hasebrink, U., Livingstone, S., \& Haddon, L. (2008). Comparing children's online opportunities and risks across Europe: Cross-national comparisons for EU Kids Online. London: EU Kids Online (Deliverable D3.2).

Hayes, F. A., \& Preacher, J. K. (2014). Statistical mediation analysis with a multicategorical independent variable. British Journal of Mathematical and Statistical Psychology, 67, $451-470$.

Hayne, S. C., \& Rice, R. E. (1997). Attribution accuracy when using anonymity in group support systems. International Journal of Human-Computer Studies, 47(3), 429452. doi:10.1006/ijhc.1997.0134.

Jennings, M.K. (1989). The crystallization of orientations. In: Continuities in Political Action. M.K. Jennings et al. (Eds.). New York: Walter de Gruyter. (pp. 313348).

Jessup, L. M., Connolly, T., \& Tansik, D. A. (1990). Toward a theory of automated group work: The deindividuating effects of anonymity. Small Group Research, 21(3), 333-348. doi:10.1177/1046496490213003.

Johnson, D. D., McDermott, R., Cowden, J., \& Tingley, D. (2012). Dead certain: Confidence and conservatism predict aggression in simulated international crisis decision-making. Hum Nat, doi:10.1007/s12110-012-9134-z.

Jones, T. (2008). A deadly web of deceit: A teen's online friend proved false, and cybervigilantes are avenging her. Retrieved January 10, 2008, from http://www.washington post.com /wp dyn/content/article/2008/01/09/AR2008010903367pf.html.

Jost, J., \& Banaji, M. (1994). The role of stereotyping in system-justification and the production of false consciousness. British Journal of Social Psychology, 33(1), $1-27$.

Jost, J., Kruglanski, A., Glaser, J., \& Sulloway, F. (2003). Political Conservatism as Motivated Social Cognition. Psychological Bulletin, 129(3), 339-375. doi: 10.1037/0033-2909.129.3.339.

Kann, L., Kinchen, S., Shanklin, S. et al. (2013). Youth Risk Behavior Surveillance CDC-MMWR, 1-162. 
Kiesler, S., Siegel, J., \& McGuire, T. W. (1984). Social psychological aspects of computer-mediated communication. American Psychologist, 39(10), 1123-1134. doi:10.1037/0003-066X.39.10.1123.

King, M., \& Bruner, C. (2000). Social Desirability Bias: A Neglected Aspect of Validity Testing. Psychology \& Marketing, 17(2), 79- 103.

Koenig, H. G. (2008). Medicine, religion and health: where science and spirituality meet. West Conshohocken, PA: Templeton Foundation Press.

Krebs, D. L. (1970). Altruism: An examination of the concept and a review of the literature. Psychological bulletin, 73(4), 258.

Krebs, D. L. (2015). Prosocial behavior. In Evolutionary perspectives on social psychology (pp. 231-242). Springer International Publishing.

Lagerspetz, K. M., Björkqvist, K., \& Peltonen, T. (1988). Is indirect aggression typical of females? Gender differences in aggressiveness in 11- to 12-year-old children. Aggressive Behavior, 14(6), 403-414. doi:10.1002/10982337(1988)14:6<403::AID-AB2480140602>3.0.CO;2-D.

Landau, S. F., Björkqvist, K., Lagerspetz, K. M., Osterman, K., \& Gideon, L. (2002). The effect of religiosity and ethnic origin on direct and indirect aggression among males and females: Some Israeli Findings. Aggressive Behavior, 28, 281-298.

Lee, J.J. (2002). Religion and college attendance: Change among students. The Review of Higher Education, 25, 369-384.

Lenhart, A. (2009). Teens and Sexting: How and why minor teens are sending sexually suggestive nude or nearly nude images via text messaging. Pew Research Center.

Li, Q. (2007). New bottle but old wine: A research on cyberbullying in schools. Computers and Human Behavior, 23, 1777-1791.

Livingstone, S. \& Haddon, L. (2008). Risky experiences for children online: Charting European research on children and the Internet. Children and Society, 22, 314323.

Manganelli Rattazzi, A. M., Bobbio, A., \& Canova, L. (2007). Right-Wing Authoritarianism-Revised Scale [Database record] Retrieved from PsycTESTS. doi: $10.1037 / \mathrm{t} 03561-000$. 
McGregor, H. A., Lieberman, J. D., Greenberg, J., Solomon, S., Arndt, J., Simon, L., \& Pyszczynski, T. (1998). Terror management and aggression: evidence that mortality salience motivates aggression against worldview-threatening others. Journal of personality and social psychology, 74(3), 590.

McKenna, K. A., \& Bargh, J. A. (2000). Plan 9 from cyberspace: The implications of the Internet for personality and social psychology. Personality And Social Psychology Review, 4(1), 57-75. doi:10.1207/S15327957PSPR0401_6.

McKenna, K. A., \& Bargh, J. A. (1998). The computers that bind: Relationship formation on the Internet. Unpublished doctoral dissertation, Ohio University.

McKiernan, A., Ryan, P., McMahon, E., \& Butler, E. (2017). Qualitative Analysis of Interactions on an Online Discussion Forum for Young People with Experience of Romantic Relationship Breakup. Cyberpsychology, Behavior, and Social Networking, 20(2), 78-82.

Mitchell, K. J., Wolak, J., \& Finkelhor, D. (2007). Trends in youth reports of sexual solicitations, harassment and unwanted exposure to pornography on the Internet. Journal of adolescent health, 40(2), 116-126.

Morahan-Martin, J., \& Schumacher, P. (2003). Loneliness and social uses of the Internet. Computers in Human Behavior, 19(6), 659-671.

Moral-Toranzo, F., Canto-Ortiz, J., \& Gómez-Jacinto, L. (2007). Anonymity effects in computer-mediated communication in the case of minority influence. Computers In Human Behavior, 23(3), 1660-1674. doi:10.1016/j.chb.2005.09.002.

Moorman, R. H., \& Podsakoff, P. M. (1992). A meta-analytic review and empirical test of the potential confounding effects of social desirability response sets in organizational behavior research. Journal of Occupational and Organizational Psychology, 65, 131-149.

O’Sullivan, P. B., \& Flanagin, A. J. (2003). Reconceptualizing “flaming” and other problematic messages. New Media \& Society, 5, 69-94.

Ottoni-Wilhelm, M., Estell, D. B., \& Perdue, N. H. (2014). Role-modeling and conversations about giving in the socialization of adolescent charitable giving and volunteering. Journal of adolescence, 37(1), 53-66.

Patton, D. U., Hong, J. S., Ranney, M., Patel, S., Kelley, C., Eschmann, R., \& Washington, T. (2014). Social media as a vector for youth violence: A review of the literature. Computers in Human Behavior, 35, 548-553. 
Pauwels, L., \& Schils, N. (2016). Differential online exposure to extremist content and political violence: Testing the relative strength of social learning and competing perspectives. Terrorism and Political Violence, 28(1), 1-29.

Pettersson, T. (1991). Religion and criminality: Structural relationships between church involvement and crime rates in contemporary Sweden. Journal Scientific Study Religion, 30, 279-291.

Pew Research Center (2015). "Social Media Usage: 2005-2015". http://www.pewinternet.org/2015/10/08/social-networking-usage-2005-2015/

Powell, K. B. (1997). Correlates of violent and nonviolent behavior among vulnerable inner-city youths. Family Community Health, 20, 38-47.

Prentice-Dunn, S., Rogers, R. W. (1980). Effects of deindividuating situational cues and aggressive models on subjective deindividuation and aggression. Journal of Personality and Social Psychology, 39, 104-113.

Prot, S., Gentile, D. A., Anderson, C. A., Suzuki, K., Swing, E., Lim, K. M., ... \& Liau, A. K. (2014). Long-term relations among prosocial-media use, empathy, and prosocial behavior. Psychological science, 25(2), 358-368.

Reicher, S. D., Spears, R., \& Postmes, T. (1995). A social identity model of deindividuation phenomenon. European Review of Social Psychology, 6, 161198.

Robertson, T. (2006). Dissonance effects as conformity to consistency norms: The effect of anonymity and identity salience. British Journal of Social Psychology, 45(4), 683-699. doi:10.1348/014466605X82855.

Rushton, J. P., \& Cambell, A. C. (1976). Modeling, vicarious reinforcement and extraversion on blood donating in adults. Immediate and long-term effects. European Journal of Social Psychology, in press.

Russell, D , Peplau, L. A.. \& Ferguson, M. L. (1978). Developing a measure of loneliness. Journal of Personality Assessment, 42, 290-294.

Schaller, M., \& Neuberg, S.L. (2012). Anger, disease, and the nature of prejudice(s). J. Olson \& M. P. Zanna (Eds.), Advances in Experimental Social Psychology (Vol. 46, pp. 1 - 55). Burlington, VT: Academic Press.

Shen, M., Rowatt, W., \& LaBouff, J. (2012). Religiosity and Prejudice Revisited: InGroup Favoritism, Out-Group Derogation, or Both? Psychology of Religion and Spirituality, 4(2):154-168. 
Spears, R., \& Lea, M. (1992). Social influence and the influence of the 'social' in computer-mediated communication. In M. Lea, M. Lea (Eds.), Contexts of computer-mediated communication (pp. 30-65). Hertfordshire, HP2 7EZ England: Harvester Wheatsheaf.

Spears, R., Lea, M., Corneliussen, R. A., Postmes, T., \& Ter Haar, W. (2002). Computermediated communication as a channel for social resistance: The strategic side of SIDE. Small Group Research, 33, 555-574.

Snell, P. (2010). Emerging adult civic and political disengagement: A longitudinal analysis of lack of involvement with politics. Journal of Adolescent Research, $25,258-287$.

Smith, M., \& Berge, Z. (2009). Social Learning Theory in Second Life. Journal of Online Learning and Teaching, 5(2), 439-445.

Staub, E. (2013). Positive social behavior and morality: Social and personal influences. Elsevier.

Suler, J. (2004). The online disinhibition effect. Cyberpsychology \& Behavior, 7(3), 321326.

Tanis, M., \& Postmes, T. (2007). Two faces of anonymity: Paradoxical effects of cues to identity in CMC. Computers In Human Behavior, 23(2), 955-970. doi:10.1016/j.chb.2005.08.004.

Unterrainer, H.-F., Nelson, O., Collicutt, J., \& Fink, A. (2012). Multidimensional Inventory for Religious/Spiritual Well Being. Well-Being--English Version [Database record]. Retrieved from PsycTESTS. doi: 10.1037/t15503-000.

White, G. M. (1972). Immediate and deferred effects of model observation and guided and unguided rehearsal on donating and stealing. Journal of Personality and Social Psychology, 21, 139-148.

Willoughby, T. (2008). A short-term longitudinal study of internet and computer game use by adolescent boys and girls: Prevalence, frequency of use, and psychosocial predictors. Developmental Psychology, 44, 195-204.

Ybarra, M. L. \& Mitchell, K. J. (2004). Online aggressor/targets, aggressors, and targets: a comparison of associated youth characteristics. Journal of Child Psychology and Psychiatry, 45, 1308-1316.

Yee, N., Bailenson, J. N., Urbanek, M., Chang, F. \& Merget, D. (2007). The unbearable likeness of being digital: The persistence of nonverbal social norms in online 
virtual environments. The Journal of CyberPsychology and Behavior, 10, 115121.

Yonker, J. E., Schnabelrauch, C. A., \& DeHaan, L. G. (2012). The relationship between spirituality and religiosity on psychological outcomes in adolescents and emerging adults: A meta-analytic review. Journal of Adolescence, 35, 299-314.

Zickuhr, K. \& Madden, M. (2012). Older adults and internet use. Pew Research Center's Internet \& American Life Project. Washington, DC. Retrieved June 1, 2016 from http://www.sainetz.at/dokumente/Older_adults_and internet use_2012.pdf.

Zimbardo, P. G. (1969). The human choice: Individuation, reason and order, versus deindividuation, impulse and chaos. In W. Arnold \& D. Levine (Eds.), Nebraska Symposium on Motivation: 1969. Lincoln: University of Nebraska Press.

Zimmerman, A. G., \& Ybarra, G. J. (2016). Online aggression: The influences of anonymity and social modeling. Psychology of Popular Media Culture, 5(2), 181. 
Appendix A

“Getting-to-know-you” Task

(For NOT ANONYMOUS Participants)

Please answer the following questions, this information will be accessible to the other participants that you will be interacting with. If you don't feel comfortable answering one of the questions or having one of your answers shared, please feel free to leave the field blank:

1. What area do you currently reside? (1)

2. What are you majoring in, or what do you think you will major in? (2)

3. How old are you? (3)

4. What is your favorite place to eat on campus? (4)

5. Do you have a Facebook/Twitter/Instagram account? (5)

6. Do you have family living in Miami? (6)

7. Please list your first name (7)

8. Please list your last name (8)

9. Where can you normally be found on campus when you are not in class? (9)

10. Is it difficult or easy for you to meet people? (10)

11. What is one thing happening in your life that makes you stressed out? (11)

12. If you could travel anywhere in the world, where would you go? (12)

13. What is one of your biggest fears? (13) 


\section{Appendix B}

“Getting-to-know-you” Task

(ANONYMOUS Participants)

The following questions will be based on your opinion. The "FIU Perceptions"

Task has no right or wrong answers, please answer the following questions to the best of your ability.

1. Where do you think most FIU students are from? (1)

2. What year are the majority of FIU students in? (2)

3. What do you think the majority of FIU students majoring in? (3)

4. Do you think there are more males or females at FIU? (4)

5. What do you think most students' favorite class at FIU is? (5)

6. What do you think the most popular place to eat on campus is? (6)

7. What do you think the average age of students at FIU is? (7)

8. Do you think most students miss their family while in college? (8)

9. What is one thing that happens in college that stresses most people out? (9)

10.Is it difficult for the average FIU student to meet people? (10)

11. Where do you think most people would go if they could travel anywhere in the world?(11) 
Appendix C

\section{Religiosity/Spirituality Scale:}

(1) Strongly Disagree (2) Disagree (3) Neither Agree nor Disagree (4) Agree

(5) Strongly Agree

1. I am a religious person

2. Religious ceremonies are important to me

3. I believe prayer has value

4. I believe there is a God or higher power

5. My faith gives me a feeling of security

6. I have never had a spiritual bond with anyone

7. In certain moments in my life, I feel very close to a God or a higher power

8. I feel the presence of God or a higher power in nature

9. At least once in my life, I have had an intense spiritual experience

10. In performing certain tasks, I can feel something higher or transcendent working through me

11. I believe what happens when I die is determined by how I live my life

12. I know God or a higher power is merciful

13. I see a special purpose for myself in this world

14. I try hard to life my life according to my religious belief

15. I believe in further existence after death

16. Although I cannot always understand, I believe everything happens for a reason.

17. Our flawed and often horrific behavior indicated that there is little or no meaning inherent in our existence. 
Appendix D

\section{Political Ideologies/Values Scale:}

(1) Strongly Disagree (2) Disagree (3) Somewhat Disagree (4) Somewhat Agree (5) Agree (6) Strongly Agree

1. The majority of those who criticize proper authorities in government and religious only create useless doubts in people's minds

2. What our country really needs instead of more "civil rights" is a good stiff dose of law and order

3. What our country really needs is a strong, determined leader who will crush evil, and take us back to our true path

4. People can have more than one attitude or belief and it won't necessarily fall under one political affiliation (i.e., Democrat, Republic, etc.).

5. Everyone should have their own lifestyle, religious beliefs, and sexual preferences, even if it makes them different from everyone else.

6. We should help disadvantaged groups to secure equal rights. 
Appendix E

\section{Behavioral Temptation Scale}

Imagine for a moment that you could interact with the other people who posted on the forum face-to-face. If you had been talking face-to-face/walking on campus with those other people in a real-life conversation, how tempted would you have been to do each of the behaviors below. Note that we are NOT asking whether you would have actually done each behavior, but rather the degree to which you would have been tempted to do each one. Use the scale below to indicate your response.

(1) Not at all Tempted 2-3-4-(5) Somewhat Tempted 6-7-8-(9) Very Tempted

1. Smile at the other people who posted

2. Show interest in what the other people who posted said

3. Humiliate the other people who posted in front of others

4. Purposely ignore the other people who posted

5. Make the other people who posted feel good

6. Insult or swear at the other people who posted

7. Shout or yell at the other people who posted

8. Try to the make people who posted laugh

9. Throw something at the other people who posted that could hurt him or her

10. Compliment the other people who posted

11. Put the other people who posted at ease

12. Push or shove the other people who posted

13. Treat the other people who posted nicely

14. Felt the urge to slap others who posted

15. Show that you enjoyed talking to the other people who posted

16. Threaten to hit or throw something at the other people who posted 


\section{Appendix F \\ Demographics}

1. Year of Birth (type in your answer below)

2. What is your sex?

Male Female

3. What is your primary racial identity?

Asian Black/African Descent Hispanic/Latin American Indigenous

Native White non-Hispanic/Caucasian

Other

4. What is your second racial identity?

Not Applicable Asian Black/African Descent Hispanic/Latin

American Indigenous/Native White non-Hispanic/Caucasian Other

5. What is your first familial national identity/family homeland?

6. What is your second familial national identity/family homeland?

7. How many years have you lived in the United States?

8. What is the highest level of education completed by your mother?

Some Elementary School

Elementary School

Some High School

Some College

Associates Degree

Bachelor's Degree

Some Graduate School

Masters Level Degree

Doctoral Level Degree

9. What is the highest level of education completed by your father?

Some Elementary School

Elementary School

Some High School

Some College

Associates Degree

Bachelor's Degree

Some Graduate School

Masters Level Degree

Doctoral Level Degree

10. What is your class standing?

Freshman Sophomore Junior Senior 
11. What is your current relationship status?

Single- not dating

Single-dating casually

In a relationship- less than 6 months

In a relationship- less than 2 years

In a relationship- 2 years or longer

Engaged

Married/Formal Commitment

12. Who are your preferred sexual partners?

Males Females Both

13. What was the purpose of today's study?

14. Do you think we were tricking you or deceiving you in any way today?

Yes No

15. If yes, how?

16. Did any of your friends or classmates talk to you about the study details before you came here today?

Yes No 


\section{VITA}

\section{ADAM ZIMMERMAN}

Miami, FL

2006-2010

B.S., Psychology

University of North Florida

Jacksonville, Florida

2010-2012

M.A., General Psychology

University of North Florida

Jacksonville, Florida

2013-2017

Ph.D., Psychology

Florida International University

Miami, Florida

Present

Data Analyst III

Florida International University

Miami, Florida

\section{PUBLICATIONS AND PRESENTATIONS}

Jacobson, R. K., Eaton, A. A., \& Zimmerman, A. G., (2016). How Organizational Policies Influence the Likelihood of Reporting Sexual Harassment at Work. Poster presented at the annual Society for Industrial and Organizational Psychology (SIOP) conference.

Wirth, J. H., Zimmerman, A. G, \& Turchan, P., Bernstein, M. J. Atimia: A Novel Group-based Paradigm for Manipulating Ostracism and Group Member's Performance. Group Dynamics: Theory, Research, and Practice (in press). Accepted January $7^{\text {th }}, 2014$.

Wirth, J. H., Zimmerman, A. G., \& Bernstein, M. J., (January 2012). How Do You Feel When an Inept Group Rejects You? Poster presented at the annual SPSP conference in San Diego, CA.

Wirth, J. H., Zimmerman, A. G., Love, J., \& O’Neil, D. (2011). "It Could Always be Worse": Being Ostracized by Burdensome Individuals Exacerbates Ostracism's Negative Effects. Poster presented at the annual STARS conference in Jacksonville, FL. 
Ybarra, G., Zimmerman, A. G., President, M., \& Price, K. (May, 2009). The Effectiveness of Blast: A Non-Traditional Family-Focused Intervention. Poster presented at the annual APS Conference in San Francisco, CA.

Zimmerman, A. G., \& Ybarra, G. J. (2016). Online aggression: The influences of anonymity and social modeling. Psychology of Popular Media Culture, 5(2), 181. Accepted March 24 ${ }^{\text {th }}, 2014$. 